\title{
Influence of internals on counter-current bubble column hydrodynamics: Holdup, flow regime transition and local flow properties
}

\author{
Giorgio Besagni*, Fabio Inzoli \\ Politecnico di Milano, Department of Energy, Via Lambruschini 4a, 20156 Milano, Italy
}

H I G H L I G H T S

- Counter-current bubble column is studied in annular gap and open tube configurations.

- Holdup curves in the open tube and annular gap configurations are similar in shape.

- The presence of the internals stabilizes the homogeneous regime.

- The counter-current mode increases the holdup and decreases the bubble velocity.

- The counter-current mode destabilizes the homogeneous regime.

\section{A R T I C L E I N F O}

\section{Article history:}

Received 14 June 2015

Received in revised form

23 January 2016

Accepted 6 February 2016

Available online 12 February 2016

Keywords:

Counter-current flow

Flow regime transition

Annular gap

Holdup

Optical probe

Bubble column

\begin{abstract}
A B S T R A C T
Bubble columns are frequently studied without considering internals (open tube bubble columns). However, in most industrial applications, internal devices are often added to control heat transfer, to foster bubble break-up or to limit liquid phase back mixing. These elements can have significant effects on the multiphase flow inside the bubble column reactor and the prediction of these effects is still hardly possible without experimentation. In this paper, we study experimentally a counter-current gas-liquid bubble column in the open tube and annular gap configurations. In the annular gap bubble column, two vertical internal tubes are considered. The column has an inner diameter of $0.24 \mathrm{~m}$, and the global and local hydrodynamic properties are studied using gas holdup measurements and a double-fiber optical probe. The gas holdup measurements are compared with the literature and used to investigate the flow regime transition. A double-fiber optical probe is used to acquire midpoint data and radial profiles of the local properties to study the flow properties and to further investigate the flow regime transition. The counter-current mode is found to increase the holdup, decrease the bubble velocity and cause regime transition at lower superficial gas velocity. The holdup curves in the annular gap and open tube configurations are similar in shape and values, suggesting that the presence of internals has a limited influence on the global hydrodynamic. In addition, it is found that the presence of the internals stabilizes the homogeneous regime in terms of transition gas velocity and holdup.
\end{abstract}

(c) 2016 Elsevier Ltd. All rights reserved.

\section{Introduction}

Bubble columns are frequently used in the chemical, petrochemical and food production industries. Their main advantage is a very large contact area between the liquid and gas phase, a good mixing within the liquid phase throughout the column and their low priceperformance ratio. The correct design and operation of these devices rely on the proper prediction of the flow pattern, the flow regime

\footnotetext{
* Corresponding author. Tel.: +3902 23998431.

E-mail addresses: giorgio.besagni@polimi.it (G. Besagni), fabio.inzoli@polimi.it (F. Inzoli).
}

transition, and global and local flow properties (i.e., the holdup, $\varepsilon_{G}$; the bubble rise velocity, $u_{b}$; the local void fraction, $\varepsilon_{G, \text { Local }}$; and the bubble diameter, $d_{b}$ ). The global and local flow properties of the industrial reactors may be extrapolated from the laboratory facilities applying scale-up methods (Shaikh and Al-Dahhan, 2013). Bubble columns are frequently studied without considering internals ("Open Tube", OT, bubble columns), but, in most industrial applications, internal devices are often added to control heat transfer, to foster bubble break-up or to limit liquid phase back mixing (Youssef Ahmed et al., 2013). These elements can have significant effects on the multiphase flow inside the bubble column reactor and the prediction of these effects is still hardly possible without experimentation (Youssef 
Ahmed et al., 2013). In particular, annular gap bubble columns are reactors with vertical internal tubes. Understanding the two-phase flow inside such devices is relevant for some important practical applications. Annular gap configurations can occur in internal-loop, air-lift bubble columns and in photo-catalytic bubble column reactors containing lamps positioned on their centerline (Youssef Ahmed et al., 2013). The influx of gas, oil and water inside a wellbore casing represents a multiphase flow inside concentric or eccentric annuli (Das et al., 1999a, 199b; Hasan and Kabir, 1992, 2010; Kelessidis and Dukler, 1989; Lage and Time, 2002). In addition, annular channels have been found to replicate some of the phenomena found in these more complex geometries, such as in heat exchangers, separators, fuel bundles and steam generators. The availability of experimental data on such configuration is relatively scarce and further experimental investigations are needed for establishing a reliable dataset for model validation and scale-up purposes. Bubble columns are operated in the co-current, counter-current or semi-batch mode. While the cocurrent or semi-batch modes are widely studied, the countercurrent mode is less investigated (Leonard et al., 2015) and - for the same reason reported above - ad-hoc experimental investigations should be performed.

Whereas the majority of studies have focused on open tubes running in co-current or semi-batch mode (Leonard et al., 2015), this study investigates a $d_{c}=0.24 \mathrm{~m}$ inner-diameter counter-current annular gap bubble column and the influence of the internals on the two-phase flow. The diameter of the column $\left(d_{c}=0.24 \mathrm{~m}\right)$ and its height $\left(H_{c}=5.3 \mathrm{~m}\right)$ were chosen considering the wellknown scale-up criteria for the: results obtained in a bubble column having $d_{c}>0.15 \mathrm{~m}$ and $H_{c} / d_{c}>5$ may be considered representative of larger systems (Kantarci et al., 2005; Leonard et al., 2015). Moreover, the pipe considered in this study has an inner diameter of $0.24 \mathrm{~m}$, which is a large diameter pipe under the ambient operating conditions, based on the dimensionless diameter $D_{H}^{*}$ proposed by Kataoka and Ishii (1987):

$D_{H}^{*}=\frac{D_{H}}{\sqrt{\sigma / g\left(\rho_{L}-\rho_{G}\right)}}$

where $D_{H}$ is the hydraulic diameter, $\sigma$ is the surface tension coefficient, $g$ is the gravity acceleration and $\rho_{L}-\rho_{G}$ is the density difference between the two phases. Pipes with dimensionless diameters greater than the critical value $D_{H, c r}^{*}=52$ are considered to be large diameter pipes (Brooks et al., 2012). Considering air and water under atmospheric conditions, the critical hydraulic diameter is $D_{\mathrm{H}, \mathrm{cr}} \approx 0.13 \mathrm{~m}$. When the pipe diameter is larger than this value, the stabilizing effect of the channel wall on the interface of the Taylor bubbles becomes lower, and the slug flow can no longer be sustained due to the Rayleigh-Taylor instabilities. The hydrodynamic properties in large pipes differ from the flow in small pipes because of changes in the liquid field around the bubbles, the presence of additional turbulence and strong secondary recirculation (Shawkat and Ching, 2011). Therefore, the flow regime maps and flow regime transition criteria used to predict the behavior of two-phase flow in small pipes may not be scaled up to understand the flow in large ones. Our experimental facility has a dimensionless diameter of $D_{H}^{*}=88.13$, without considering the internal tubes, and of $D_{H}^{*}=47.37$ in the annular gap configuration. Such values are higher than the ones commonly investigated in the literature and the present experimental setup differs from the ones previously investigated, as discussed in literature survey proposed by Besagni et al. (2015). Besagni et al. (2015) reviewed the studies about the counter-current two-phase flow in vertical pipes and the two-phase flow in annulus channels. The remaining of the introduction expands the literature survey by analyzing the literature concerning bubble columns with internals and the influence of the liquid velocity on bubble column hydrodynamics.
It is not clear if (and how) the presence of internal tubes in a largediameter bubble column may affect the hydrodynamics in terms of flow regime transition and holdup. Indeed, few studies concerning the hydrodynamic of bubble columns with internals can be found in the literature. Carleton et al. (1967) studied different column diameter $(0.076 \mathrm{~m}, 0.153 \mathrm{~m}$ and $0.305 \mathrm{~m})$ with different internal tubes (with size ranging from 0.025 to $0.076 \mathrm{~m}$ ). The authors reported an increase of the holdup in the annular gap configuration. Yamashita (1987) studied three different columns $(0.08,0.16$ and $0.31 \mathrm{~m}$ inner diameter) and the influence of inner tubes on gas holdup. They reported an increase of the holdup if compared with the case without inner tubes. Yamashita also found that gas holdup does not depend on the arrangement of vertical tubes; however, it increased with both their number as well as with their outer diameter. O'Dowd et al. (1987) studied a slurry bubble column (0.108 $\mathrm{m}$ inner diameter) with and without internal baffles (five tubes with outer diameter of $0.019 \mathrm{~m}$ diameter). The gas holdup increases in the baffled column as compared to the un-baffled one, and bubble size increases in the baffled column at high gas velocities. Jhawar et al. (Jhawar and Prakash, 2014) studied a $0.15 \mathrm{~m}$ column and compared the gas holdup, local liquid velocity and bubble fractions holdups obtained with and without internals $(0.0127 \mathrm{~m}$ outer diameter). The holdup may increase or decrease depending on the configuration and disposition of the internal tubed. Maurer et al. (2015) studied the influence of inner tubes (with outer diameter ranging from 0.01 to $0.02 \mathrm{~m}$ ) in a $0.14 \mathrm{~m}$ column by using $\mathrm{x}$ ray tomography. The authors reported a reduction in bubble size for the case with vertical internals. Al-Oufi et al. (2010, 2011) investigated an annular gap bubble column, using different inner tube diameters $(0.025,0.038,0.051$ and $0.070 \mathrm{~m})$ placed concentrically inside the outer column of $0.102 \mathrm{~m}$. The authors found higher holdup in the open tube column design

Considering the influence of the inner tubes over the two-phase flow, it is relevant to refer to the studies concerning the effect of column diameter in a bubble column. The data of Fair et al. (1962) and Yoshida and Akita (1965) show that the effect of the column diameter on the gas hold-up is negligible for columns larger than $0.15 \mathrm{~m}$. Hughmark (1967) has found an effect of column size on gas hold-up up to a diameter of $0.10 \mathrm{~m}$. Kato et al. (1972) conducted measurements in 0.066-, 0.122 and 0.214 m columns and found that the gas hold-up increases with decreasing column size. Koide et al. (1979) measured the gas hold-up in a $0.55 \mathrm{~m}$ column and found no significant difference from the literature values reported for columns less than $0.60 \mathrm{~m}$ in diameter. Deckwer et al. (1980) found a difference in hold-up between a $0.041 \mathrm{~m}$ column and a $0.10 \mathrm{~m}$ column. Hikita et al. (1980) measured hold-up in a $0.10 \mathrm{~m}$ column and compared their results with the ones reported in the literature for columns larger than $0.10 \mathrm{~m}$, finding no appreciable effect of the column diameter on the holdup. Gopal and Sharma (1983) measured the gas hold-up in $0.2,0.6$ and $1.0 \mathrm{~m}$ columns and concluded that the column diameter and sparger do not significantly influence the gas hold-up values. Nottenkamper et al. (1983) measured the gas holdup in $0.19,0.45$ and $1.0 \mathrm{~m}$ columns and obtained comparable results for the 0.19 and $0.45 \mathrm{~m}$ columns but lower hold-up values for the $1 \mathrm{~m}$ column at high gas rates, which they attributed to the larger diameter. Koide et al. (1984) observed smaller gas hold-up values in columns smaller than $0.2 \mathrm{~m}$. Despite some contradictory results in the literature, it appears that most investigators consider a column size of $0.10-0.30 \mathrm{~m}$ large enough to obtain gas hold-up values that can be reliably used to predict hold-up values in larger columns.

There is no general agreement on the role of liquid velocity on the hydrodynamics of the bubble columns, and studies focused on counter-current bubble columns are still limited. Akita and Yoshida (1973) have studied the effect of the liquid flow rate on the gas hold-up in a column $0.152 \mathrm{~m}$ in diameter. They have concluded that the effect of the liquid flow rate is negligible for superficial liquid velocities up to $0.04 \mathrm{~m} / \mathrm{s}$, either in gas-liquid counter- 
current or concurrent operation. Contrarily, Otake et al. (1981) observed an increase in the holdup and earlier regime transitions as the counter-current liquid flow rate is increased in a small pipe with a diameter of $0.05 \mathrm{~m}$. Their analysis covered gas superficial velocities up to $0.0824 \mathrm{~m} / \mathrm{s}$ and liquid superficial velocities up to $-0.15 \mathrm{~m} / \mathrm{s}$. Baawain et al. (2007) concluded that the countercurrent or co-current operations influenced the holdup for approximately $5 \%$ in weight, and less than $1 \%$ on bubble size, showing that the effect observed is mainly caused by the changes in the bubble rise velocity and not only caused by the bubble size. Biń et al. (2001) observed an increase in the holdup in countercurrent mode and a decrease in co-current mode. The effect is more pronounced at high gas velocity and the difference in the holdup between co-current and counter-current mode is around 10\%. The same trends were observed by Jin et al. (2010) $\left(d_{c}=0.160 \mathrm{~m}, H_{c}=2.5 \mathrm{~m}\right)$, who reported a maximum difference of $2 \%$ between counter-counter and co-current mode.
The aim of this work is to extend the existing dataset by investigating a novel configuration which may represent an industrial apparatus. Indeed, there is a lack of studies investigating the counter-current flow in a large-diameter columns and the influence of internals over the hydrodynamics and the flow regime transition. The very first experimental results of the annular gap configuration have been reported (Besagni et al., 2014, 2015; Besagni and Inzoli, 2016), but some open unsolved issues remain concerning the influence of the inner tubes on the hydrodynamics of the system. To this end, in this paper, we present an experimental investigation aimed at studying the influence of the inner tubes over the holdup curves and the regime transition. In this paper, the two-phase flow is studied by using gas holdup measurements and double-fiber optical probes. The bed expansion technique was used to obtain gas holdup measurements, which are compared with existing correlations and used to investigate the flow regime transition. The local data and radial profiles of the

a

Pump

Interception Valve

Regulation Valve

Pressure Gauge

Pressure Reducer

Flow Meters

$\square$ Nr. Rangr

$\nabla \# 1 \quad 9-93$

\#2 20-290

$\# 3$

26,7-267

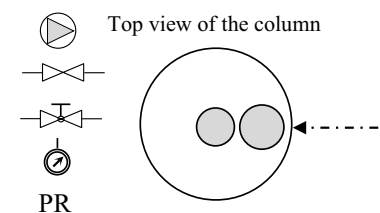

Air to vent

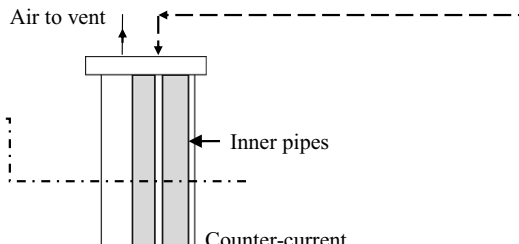

column

$\mathrm{Nl} / \mathrm{min}$
$1 / \mathrm{min}$

\begin{tabular}{ll}
$\mathrm{Nl} / \mathrm{min}$ & \\
Rotameters & $\nabla$ \\
\hline
\end{tabular}

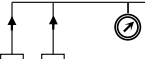

(7)

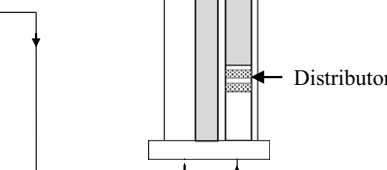

$\mathrm{mp}$

Water flow meter

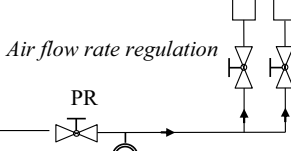

Experimental facility

b

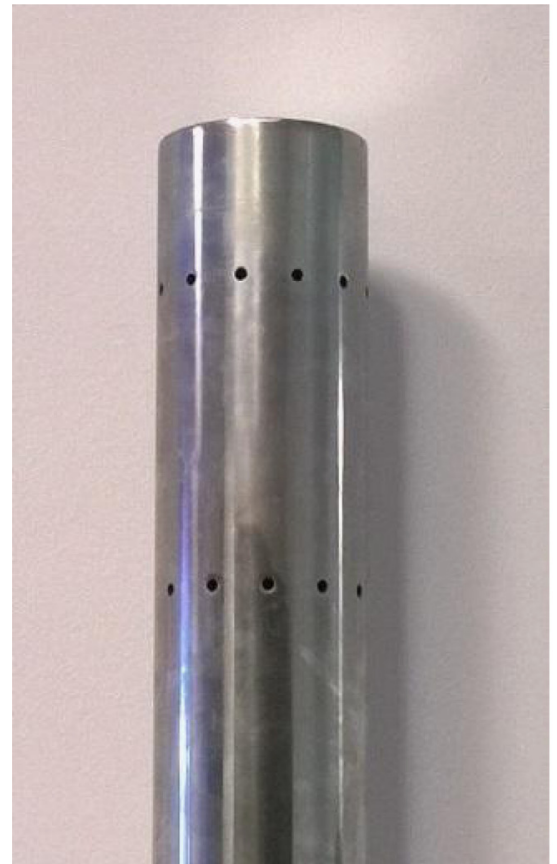

Sparger
C

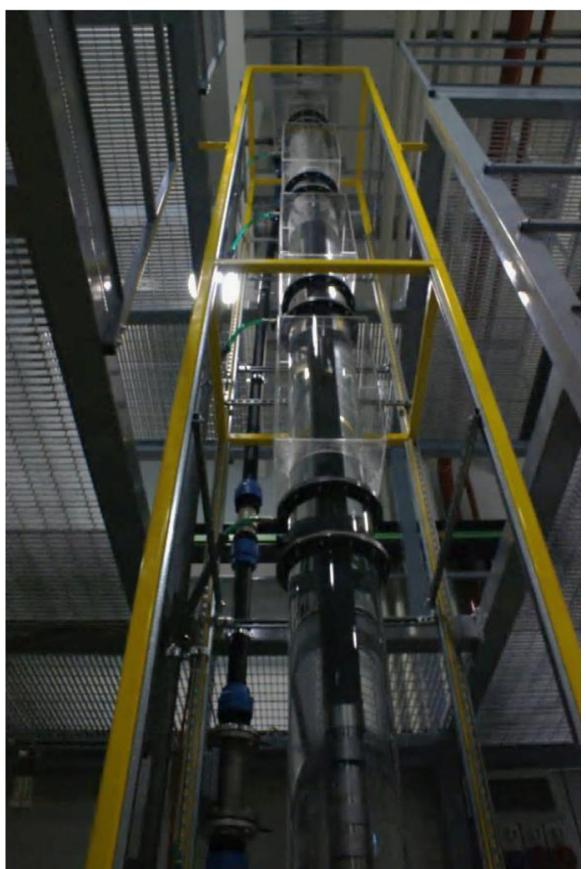

Photo of the facility

Fig. 1. Experimental facility 
local flow characteristics were obtained using a double-fiber optical probe to relate the global hydrodynamics of the system to the local flow properties.

\section{Experimental setup and method}

\subsection{Experimental setup}

The experimental facility (Fig. $1 \mathrm{a}-\mathrm{c}$ ) is a non-pressurized vertical pipe made of Plexiglas with $d_{c}=0.24 \mathrm{~m}$ and $H_{c}=5.3 \mathrm{~m}$. In the Annular Gap (AG) configuration, two internal PVC pipes are positioned: one centrally (with an external diameter of $0.060 \mathrm{~m}$ ) and one asymmetrically (with an external diameter of $0.075 \mathrm{~m}$ ). In the Open Tube (OT) configuration, there are no internal tubes. A pump, controlled by a bypass valve, provides water recirculation, and a rotameter (3) measures the water flow rate. A pressure reducer controls the pressure upstream from the rotameters (1) and (2), used to measure the air flow rate. The air distributor (Fig. 1b), which is positioned asymmetrically, is made of a stainless steel tube with an external diameter of $0.070 \mathrm{~m}$, a height of $0.340 \mathrm{~m}$ and holes positioned along the circumference with diameters $d_{\text {holes }}=3.5 \mathrm{~mm}$. Clean filtered deionized water was used and during the experiments, the air and water temperatures were held constant at room temperature $\left(22 \pm 1{ }^{\circ} \mathrm{C}\right)$.

The values of gas density (used to compute the superficial gas velocity, $U_{G}$ ) are based upon the operating conditions existing at the column mid-point. The mid-point column pressure was assumed to be equal to the column outlet pressure plus one-half the total experimental hydrostatic pressure head. The operating conditions investigated are as follows:

- in the AG configuration, $U_{G}$ up to $0.23 \mathrm{~m} / \mathrm{s}$ and $U_{L}$ of $-0.11 \mathrm{~m} / \mathrm{s}$;

- in the OT configuration, $U_{G}$ up to $0.20 \mathrm{~m} / \mathrm{s}$ and $U_{L}$ of $-0.092 \mathrm{~m} / \mathrm{s}$.

\subsection{Experimental techniques}

The holdup measurements were determined using the bed expansion technique. The local bubble properties were measured using a double-fiber optical probe. The next sections detail the measurement techniques.

\subsubsection{Gas holdup}

2.2.1.1. Gas holdup measurements. Measurements of the bed expansion allowed the evaluation of the gas holdup $\varepsilon_{G}$. The procedure involves measuring the location (height) of the liquid free surface when air flows in the column. The gas holdup is then obtained using the following relation:

$$
\varepsilon_{G}=\frac{\left(H_{D}-H_{0}\right)}{H_{D}}
$$

where $H_{D}$ and $H_{0}$ are the heights of the free surface after and before aeration, respectively. The reference height is the distributor level.

2.2.1.2. Flow regime transition analysis. Although the transition from the homogeneous to the heterogeneous regime does not occur instantaneously, the definition of an approximate transition point is helpful for modeling the hydrodynamic behavior of bubble columns. Two main transitions exist in large-diameter bubble columns: (i) the transition between the homogeneous and the transition regime and (ii) the transition between the transition regime and the heterogeneous regime. However, in the literature, lot of authors consider only the first regime transition, without any reference to the second one, except for a limited number of studies (Nedeltchev, 2015; Nedeltchev and Shaikh, 2013; Sharaf et al., 2016). In the following, for the sake of clarity, we refer to "flow regime transition point" considering the first transition. We employ two models from the literature to investigate the regime transition.

The first method is the one developed by Zuber and Findlay (1965) based on the swarm velocity:

$U_{\text {swarm }}=J_{G} / \varepsilon_{G}$

The swarm velocity is plotted against the superficial gas velocity: $U_{\text {swarm }}$ is constant in the homogeneous regime but begins to increase as the system enters the heterogeneous regime at a certain transition superficial velocity $U_{\text {trans. }}$. The appearance of the first large bubble is responsible for this sudden increase in swarm velocity and is an indication of flow regime transition. In this study, the quantitative evaluation of $U_{\text {trans }}$ is determined by the intersection between the trends of $U_{\text {swarm }}$ in the two regimes. $U_{\text {swarm }}$ is constant for the homogeneous regime:

$U_{\text {swarm,bubbly }}=$ cons

whereas in the churn turbulent flow, it is determined by a least squares fitting of the following function:

$U_{\text {swarm, churn }}=S_{1}\left(J_{G}\right)^{S_{2}}+S_{3}$

where $S_{1}, S_{2}$ and $S_{3}$ are fitting parameters. The transitional velocity is then evaluated by solving the following equation:

$U_{\text {swarm,bubbly }}=U_{\text {swarm, churn }}$

The second method is the drift-flux plot proposed by Wallis (1969) and has been widely applied in the literature. This method is based on the drift flux, which represents the gas flux through a surface moving with the speed of the two-phase mixture and is experimentally obtained as follows:

$U_{T}=U_{G}\left(1-\varepsilon_{G}\right) \pm U_{L} \varepsilon_{G}$

which, for a counter current flow, reads as follows:

$U_{T}=U_{G}\left(1-\varepsilon_{G}\right)+U_{L} \varepsilon_{G}$

The reader should refer to Appendix A for the derivation of (Eqs. (7) and 8).

Theoretically, the drift flux is written in terms of the bubble swarm velocity, whose dependence upon $\varepsilon \varepsilon$ varies with the prevailing regime:

$J_{E}=U_{b}\left(1-\varepsilon_{G}\right)$

The idea in this method is to employ a model for $U_{b}$ that is valid for the homogeneous regime, plotting $J_{E}$ and $J_{T}$ in the same graph as a function of $\varepsilon_{G}$. In the homogeneous regime, $J_{E}$ is equal to $J_{T}$, and the transition point is defined when

$J_{T} \neq J_{E}$

The evaluation of $U_{\text {swarm }}$ is a matter of discussion in the literature, and different models have been proposed and applied. In this study, we follow the approach of Krishna et al. (2000), which is based on the empirical model of Richardson and Zaki (1997):

$U_{b}=u_{\infty} \varepsilon_{G}\left(1-\varepsilon_{G}\right)^{n-1}$

where $n$ is fluid-dependent ( $n \cong 2$ for water) and should be fitted with the aid of the experimental data, together with $u_{\infty}$, the terminal velocity of an isolated bubble, in the determination of the regime transition point. From (Eqs. (9) and 11), we obtain the following:

$J_{E}=u_{\infty} \varepsilon_{G}\left(1-\varepsilon_{G}\right)^{n}$ 


\subsubsection{Optical probe}

The local bubble properties were measured using a doublefiber optical probe. The optical probe is inserted, via an access port, into the flow at a height of $h_{\text {probe }}=2.3 \mathrm{~m}$ from the bottom of the column ( $1.9 \mathrm{~m}$ from the air distributor).

2.2.2.1. Instrumentation. A double-fiber optical probe system (manufactured by RBI) measures the local flow properties (local void fraction, bubble vertical velocity, bubble Sauter mean diameter, interfacial area concentration and bubble chord length distributions). Similar optical probe systems have been used by different authors (Besagni and Inzoli, 2015; Chaumat et al., 2005; Kiambi et al., 2003; Lima Neto et al., 2008; Simonnet et al., 2007; Zhang and Zhu, 2013).

Optical probes distinguish the gas and liquid phases by measuring the intensity of a laser light that is reflected and/or refracted at the probe tip based on the refractive indexes of the probe tip, gas and liquid phases (Barrau et al., 1999). The probe signal is measured via an optoelectronic module, which emits the laser to the probe tip and converts the reflected optical signal into a digital signal. From the digital signal, the bubble frequency $f$ (bubble number per unit time) and void fraction $\varepsilon_{G, \text { Local }}$ (assuming it equals the proportion of time when the tip is surrounded by gas) can be obtained. By cross-correlating the signals from the two tips, the bubble traveling time from one tip to the other can be estimated, and the bubble velocity $u_{b}$ can be calculated. A precise description of how each variable is measured by the optical probe was proposed by Chaumat et al. (2007) and is not repeated here.

Assuming that the bubbles are spherical, the bubble Sauter mean diameter $d_{b}$ is calculated accordingly with Kataoka et al. (1986):

$d_{b}=3 \varepsilon_{G, \text { Local }} u_{b} / 2 f$

Eq. (13) is based on the assumption of spherical bubbles; however, this assumption is only approximately valid when the bubbles are small. The following equation has been used to account for the non-sphericity of bubbles (Simonnet et al., 2007):

$d_{b, \text { corrected }}=\varphi^{-2 / 3} 3 \varepsilon_{G, \text { Local }} u_{b} / 2 f$

where $\varphi$ is the aspect ratio.

2.2.2.2. Measurement locations. Using the optical probes, the following data have been obtained:

- AG configuration. The optical probes have been used to acquire data at a single point (Fig. 2a) for different superficial gas and liquid velocities.

- OT configuration. The optical probes have been used to acquire data in the center of the column (midpoint position) for a wide

a

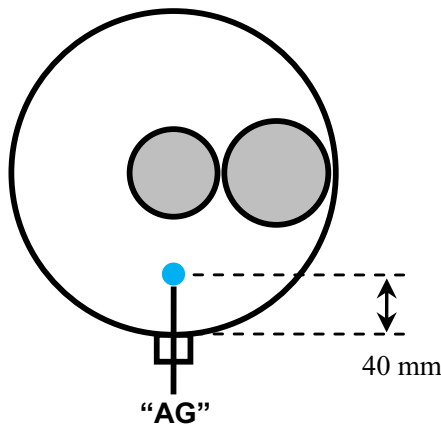

b

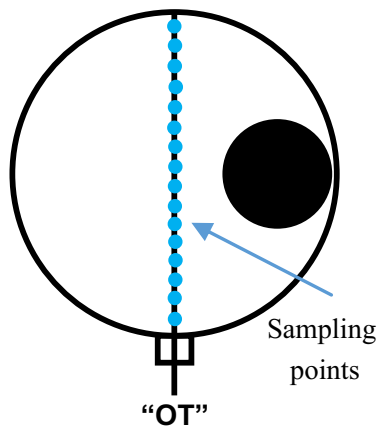

Fig. 2. Optical probe sampling positions. range of operating conditions. Furthermore, at $U_{L}=0 \mathrm{~m} / \mathrm{s}$ (batch mode), 5 radial profiles (Fig. 2b) in homogeneous regime and 3 in transition/heterogeneous flow have been acquired. Finally, to investigate the counter-current operating condition, 3 radial profiles in bubbly and transition/heterogeneous flow have been acquired for $U_{L}=-0.08 \mathrm{~m} / \mathrm{s}$ (counter-current mode).

2.2.2.3. Sampling period. All of the above-mentioned measurements have been obtained using a sampling period equal to $\Delta t_{\text {sampling }}=1000 \mathrm{~s}$, which is large enough to produce reliable timeaveraged values. Moreover, this measurement period is far above the typical values of $1-5$ min for similar optical probes (Chang et al., 2003; Chaumat et al., 2005; Lima Neto et al., 2008; Zhang and Zhu, 2013).

2.2.2.4. Optical probe sources of errors. There are some potential sources of error when characterizing bubbles using optical probes (Vejražka et al., 2010):

- improper dewetting at the probe tip (the blinding effect);

- alteration of the bubble trajectory before or during the piercing process (the drifting effect);

- bubble deformation and/or deceleration at the probe tip (the crawling effect).

Both the blinding effect and the crawling effect include deformation effects. The deformation of the blinding effect is mainly related to a local deformation zone located in the bubble interface, which may be produced by both the probe-induced liquid pressure over the bubble and the direct impact itself. The crawling effect considers the deformation of large parts of the bubble. The relative influence of these effects on the final residence time estimates, as well as their absolute magnitude, is not yet clear. A summary of the errors reported by the optical probe in the literature is as follows:

- Void fraction. Generally, the optical probe is considered rather accurate in terms of void fraction. Comparing optical probe results with other measurement techniques (i.e., visual or pressure sensors), the relative differences found in the literature are as follows: between $-0.8 \%$ and $-16 \%$ according to Barrau et al. (1999); $-2.2 \%$ (Zhang and Zhu, 2013); - 3\% (Chang et al., 2003); $-11 \%$ (Lima Neto et al., 2008); between $-6 \%$ and $-14 \%$ (Kiambi et al., 2003); and $+12 \%$ (Simonnet et al., 2007). Barrau et al. observed the worst performance with no liquid flow and/ or at low gas fractions.

- Bubble rise velocity. The rise time errors are primarily affected by the impact angle of the bubbles with the probe tip. The relative difference reported in the literature, compared with other techniques (i.e., image processing) are $+45 \%$ (Cartellier and Barrau, 1998); +5\% (Kiambi et al., 2003); between $+5 \%$ and $+6 \%$ (Chang et al., 2003); between $+10 \%$ and $+30 \%$ (Chaumat et al., 2005); + 15\% (Simonnet et al., 2007); +29\% (Lima Neto et al., 2008); and approximately $+9 \%$ (Zhang and Zhu, 2013).

- Bubble diameter. The assumption of spherical bubbles leads to an underestimation of the equivalent diameter by between $+10 \%$ and 27\% (Chaumat et al., 2005; Lima Neto et al., 2008; Zhang and Zhu, 2013). Applying a correction based on the aspect ratio evaluation can reduce the error, e.g., from $+26.6 \%$ to $+7 \%$ (Zhang and Zhu, 2013).

\section{Results}

This section details the experimental results. First, the holdup measurements are presented and used to obtain information on 
a

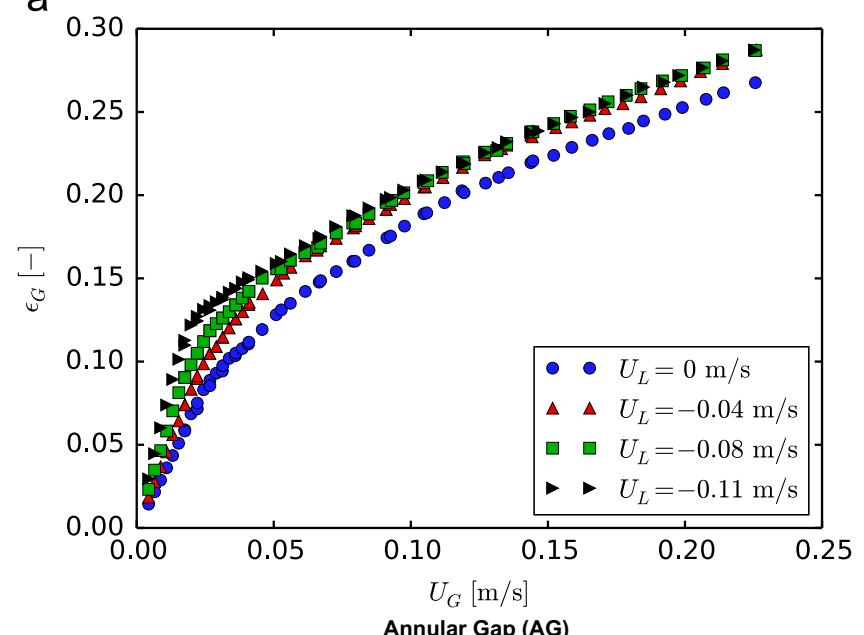

b

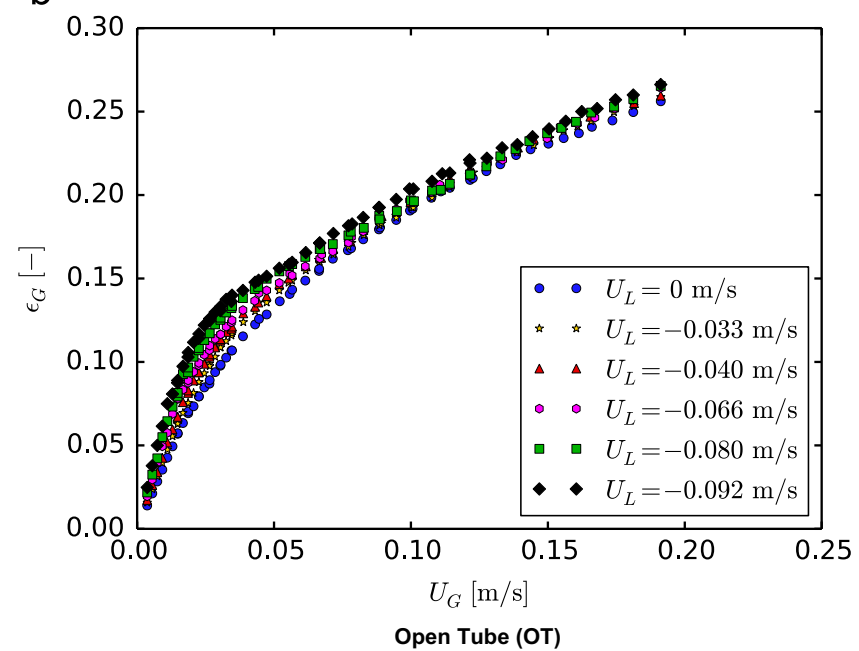

Fig. 3. Gas holdup: measurements.

the global hydrodynamics and flow regime transitions. Second, optical probe data are presented and used to investigate the local flow behavior.

\subsection{Gas holdup}

\subsubsection{Gas holdup measurements}

Fig. 3a presents the holdup measurements for the AG configuration. At low air superficial velocity, in the homogeneous regime, the relationship between the gas holdup and the air superficial velocity is linear, followed by a change in slope due to flow regime transition. Upon increasing the liquid flow rate, a faster increase in the holdup is observed at low superficial gas velocities, and the transition point also moves toward lower superficial gas velocities. This change is explained by the effect of the liquid flow, which slows down the rise of the bubbles, leading to higher holdup: the more compact arrangement of the bubbles leads to an earlier flow regime transition (Section 3.2). This phenomenon is further investigated by the optical probe measurements in Section 3.3. Above the transition velocity, large deformed bubbles (the "coalescence induced" bubbles, (Urseanu, 2000)) appear and the bubble coalescence increases the average rise velocity and reduces gas residence time in the column, hence decreasing the gas holdup versus gas velocity slope. In the transition/heterogeneous regime, the slope of the curves changes continuously indicating a continuous increase of the "coalescence induced" bubbles (Urseanu, 2000). The slope of the holdup curves is the one typically found for similar sparger design and, as expected, no peak is observed (Sharaf et al., 2016; Urseanu, 2000). This was previously discussed by Besagni and Inzoli (2016). Above $\varepsilon_{G} \approx 16-$ $17 \%$, the water superficial velocity has no influence on the gas holdup. The discrepancy of the holdup in the transition/heterogeneous regime between the no liquid flow and counter-current configurations is hardly justified. One possible hypothesis may be the asymmetric distributor, which generates a larger flow development zone in the no liquid flow configuration with respect to the counter-current cases, due to the lower liquid back-mixing. Another hypothesis may be the change in the bubble size distribution in counter-current mode. The interested reader should refer to the studies of Besagni et al. $(2015,2016)$ for the flow visualizations and the image analysis for information on bubble sizes and shapes.

Fig. $3 \mathrm{~b}$ presents the holdup measurements for the OT configuration. Similar to the AG configuration, homogeneous regime and regime transition were observed. At low air superficial velocity, in the homogeneous regime, the relationship between the gas holdup and the air superficial velocity is linear, followed by a change in slope due to the flow regime transition. The absence of a stable slug flow in both configurations can be explained by large diameter column theory: the dimensionless diameter is $D_{H}^{*}=88.13$, without considering the internal tubes, and $D_{H}^{*}=47.37$ in the annular gap configuration. In addition the absence of the slug flow is in agreement with the flow map of Shah et al. (1982)

Our results may suggest that the liquid velocity influences the bubble column hydrodynamic. This result is in agreement with the findings of Otake et al. (1981), Baawain et al. (2007), Biń et al. (2001) and Jin et al. (2010), but disagrees with the results of Akita and Yoshida (1973). Our findings suggest that $U_{L}$ has an influence on the holdup owing to the comparable order of magnitude of the liquid and gas velocity. Hills (1976) mentioned that, if $U_{L}$ is low compared to the bubble rise velocities, no impact of liquid velocity on the holdup is expected as the acceleration of the bubbles will be negligible. However, in this case, the bubble swarm velocities (Section 3.2.1) are comparable in their value with the liquid velocities. Similar conclusions were derived by Rollbusch et al. (2015).

Comparing the AG and the OT configurations, the first remarkable difference is the behavior in the transition/heterogeneous regime: in the OT configuration the holdup increases, with the superficial water velocity. However, in the OT configuration, the holdup curves seem to regroup together into a single curve at higher $U_{G}$. The two bubble column designs are compared in Fig. 4 for $U_{L}=0,-0.04$ and $-0.09 \mathrm{~m} / \mathrm{s}$. The holdup values are very similar between the AG and the OT configurations: the holdup curves are similar in shape and the holdup values are comparable (Fig. 4). In particular, at $U_{L}=-0.04 \mathrm{~m} / \mathrm{s}$, the holdup curves are very close (Fig. $4 \mathrm{~b}$ ). There are small differences at $U_{L}=0 \mathrm{~m} / \mathrm{s}$ (the AG configuration has slightly lower holdup, Fig. 4a) and at $U_{L}=-0.09 \mathrm{~m} / \mathrm{s}$ (the AG configuration has a slightly higher holdup, Fig. 4c). However, these differences are very limited, suggesting that the presence of the internals has a negligible effect on the holdup curves. Investigation dealing with the comparison of the holdup for the case with and without internals and with $U_{L}=0 \mathrm{~m} / \mathrm{s}$ have been performed by Carleton et al. (1967), Yamashita (1987), O'Dowd et al. (1987) and Jhawar and Prakash (2014). Carleton et al., Yamashita et al. and O'Down et al. reported an increase of the holdup in the annular gap configuration. These results are in agreement with our findings. Jhawar and Prakash (2014) found that the holdup may increase or decrease depending on the configuration and disposition of the internal tube. Al-Oufi et al. $(2010,2011)$ found that the holdup decreases in the annular gap configuration $\left(U_{L}=0 \mathrm{~m} / \mathrm{s}\right)$, which is in disagreement with our finding. However, Al-Oufi et al. $(2010,2011)$ have tested a small diameter bubble column with a porous sparger, which is a very different configuration from the present one. Our results suggest 
a

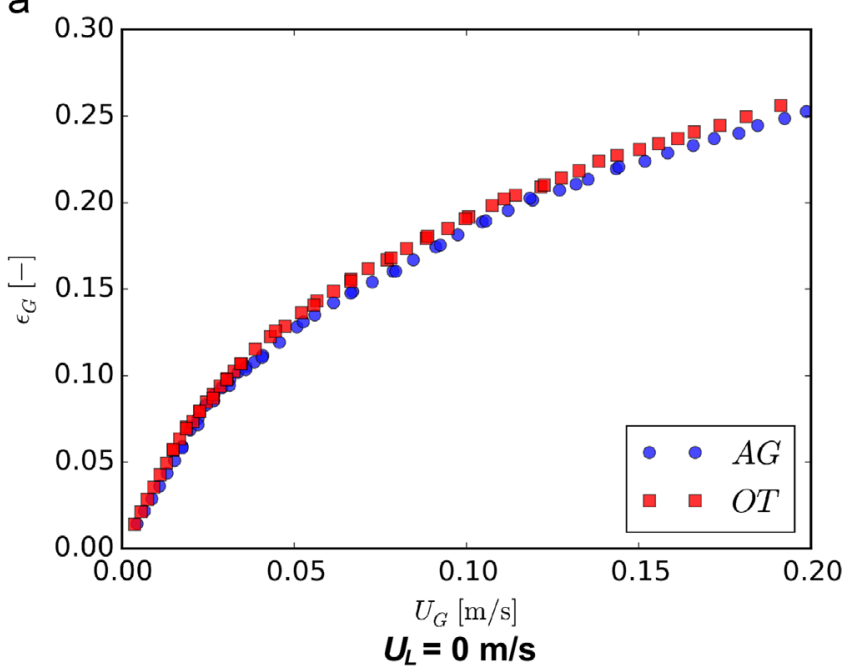

b

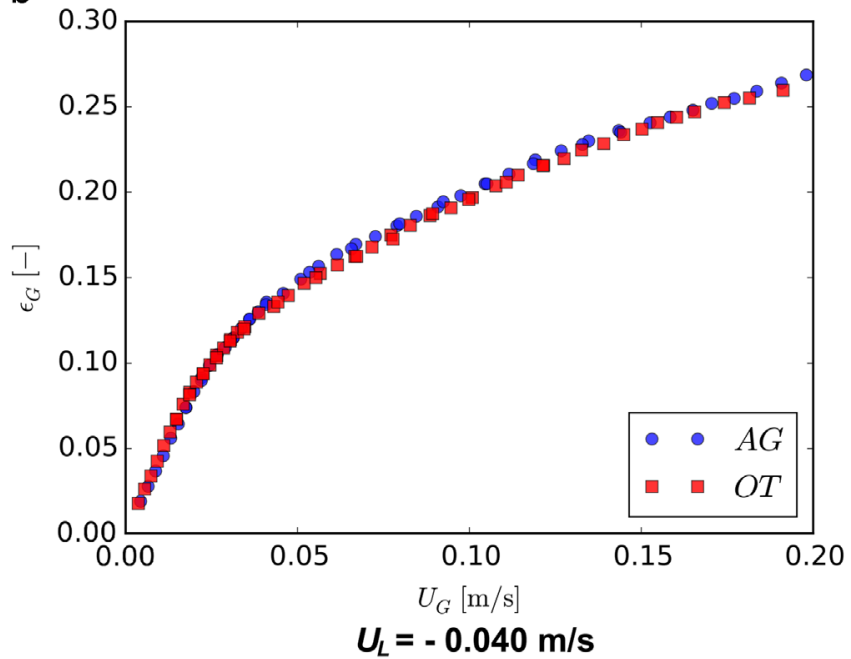

C

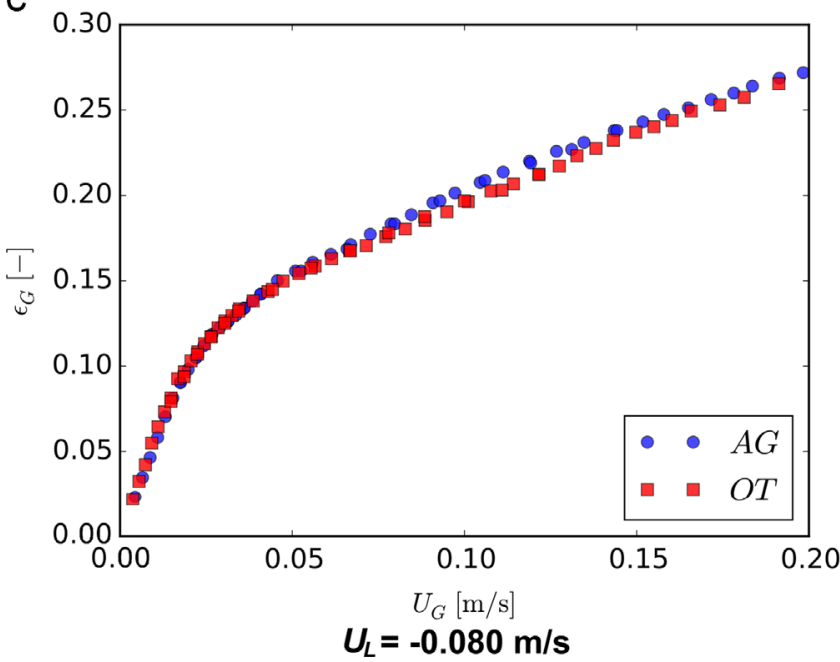

Fig. 4. Gas holdup: comparison between AG and OT configurations.

that the presence of internals has a limited influence over the holdup curves, probably because of the large-diameter of the column. The limited influence of the vertical internals on the holdup is in agreement with the rule of the thumb that $d_{c}=0.15 \mathrm{~m}$ is larger enough for the results to be scalable.
The holdup curves obtained with the AG and OT configurations (batch mode) are similar to the holdup curve obtained using same experimental facility equipped with a spider sparger (Besagni and Inzoli, 2015). This may suggest a limited influence of the sparger design in large-diameter bubble columns, possibly due to the sparger with large openings. However, this is a matter of future studies; in particular, the spider-sparger bubble column should be investigated in the counter-current mode.

3.1.2. Comparison with data and correlation from the literature 3.1.2.1. Data comparison. In the literature, assorted experimental data are available on bubble columns with various diameters. However, few studies are available on counter-current flow in large diameter columns. Moreover, experiments involving internal tubes in large diameter columns (similar to the present configuration) are almost absent. To compare the holdup data, a set of experimental studies whose column diameter and sparger design were similar to the one considered in this study have been selected. The list of references is given in Table 1 , and the data comparison is displayed in Fig. 5. The data of Al-Oufi et al. (2010) refer to the annular gap configuration with an inner tube diameter of $0.051 \mathrm{~m}$. A relatively high variability between the reference data is observed. However, the holdup results lie within the range of such variability, indicating that the two-phase flow dynamics in this experimental configuration is similar to the one in a bubble column without an inner tube.

Comparing our results with the studies focusing on the influence of internals (Carleton et al., 1967; Jhawar and Prakash, 2014; O'Dowd et al., 1987; Yamashita, 1987)-the reader may refer to the literature review in the introduction-it is clear that the changes to the holdup highly depend upon the internal layout and column design.

3.1.2.2. Correlation comparison. Many correlations have been proposed in the literature for the gas holdup. Herein, a set of correlations have been selected and compared with our data (Fig. 6):

- Hughmark (1967):

$$
\varepsilon_{G}=\frac{1}{2+\left(\frac{0.35}{U_{G}}\right)\left[\frac{\rho_{L} \sigma}{72}\right]^{1 / 3}}
$$

- Mashelkar (1970):

$$
\varepsilon_{G}=\frac{U_{G}}{0.3+2 U_{G}}
$$

- Akita and Yoshida (1973):

$$
\frac{\varepsilon_{G}}{\left(1-\varepsilon_{G}\right)^{4}}=c_{1}\left(\frac{g d_{c}^{2} \rho_{L}}{\sigma}\right)^{1 / 8}\left(\frac{g d_{c}^{3}}{\nu_{L}^{2}}\right)^{1 / 12}\left(\frac{U_{G}}{\sqrt{g d_{c}}}\right)
$$

- Hikita and Kikukawa (1974):

$$
\varepsilon_{G}=0.505 \cdot U_{G}^{0.47}\left(\frac{72}{\sigma}\right)^{2 / 3}\left(\frac{1}{\mu_{L}}\right)^{0.05}
$$

- Sada et al. (1984):

$$
\frac{\varepsilon_{G}}{\left(1-\varepsilon_{G}\right)^{4}}=0.32 \cdot\left(\frac{g d_{c}^{2} \rho_{L}}{\sigma}\right)^{0.121}\left(\frac{g d_{c}^{3}}{\nu_{L}^{2}}\right)^{0.086}\left(\frac{U_{G}}{\sqrt{g d_{c}}}\right)\left(\frac{\rho_{G}}{\rho_{L}}\right)^{0.068}
$$


Table 1

Experimental studies (code reference to Fig. 5).

\begin{tabular}{|c|c|c|c|c|}
\hline & References & Configuration & $d_{\text {column }}[\mathrm{m}]$ & Sparger design \\
\hline $\mathrm{R} 1$ & (Reith et al., 1968) & Open tube & 0.14 & Perf. Plate $-d_{\text {holes }}=2 \mathrm{~mm}$ \\
\hline $\mathrm{R} 2$ & (Reith et al., 1968) & Open tube & 0.29 & Perf. Plate $-d_{\text {holes }}=2 \mathrm{~mm}$ \\
\hline R3 & (Schumpe and Grund, 1986) & Open tube & 0.30 & Ring $-d_{\text {holes }}=1 \mathrm{~mm}$ \\
\hline $\mathrm{R} 4$ & (Wilkinson et al., 1992) & Open tube & 0.15 & Ring $-d_{\text {holes }}=2 \mathrm{~mm}$ \\
\hline R5 & (Wilkinson et al., 1992) & Open tube & 0.23 & Ring $-d_{\text {holes }}=7 \mathrm{~mm}$ \\
\hline R6 & (Thorat et al., 1998) & Open tube & 0.385 & Sieve plate $-d_{\text {holes }}=1 \mathrm{~mm}$ \\
\hline R7 & (Thorat et al., 1998) & Open tube & 0.385 & Sieve plate $-d_{\text {holes }}=2 \mathrm{~mm}$ \\
\hline R8 & (Al-Oufi et al., 2010) & Annular gap & 0.102 & Porous plate $-d_{\text {holes }}=0.1 \mathrm{~mm}$ \\
\hline
\end{tabular}

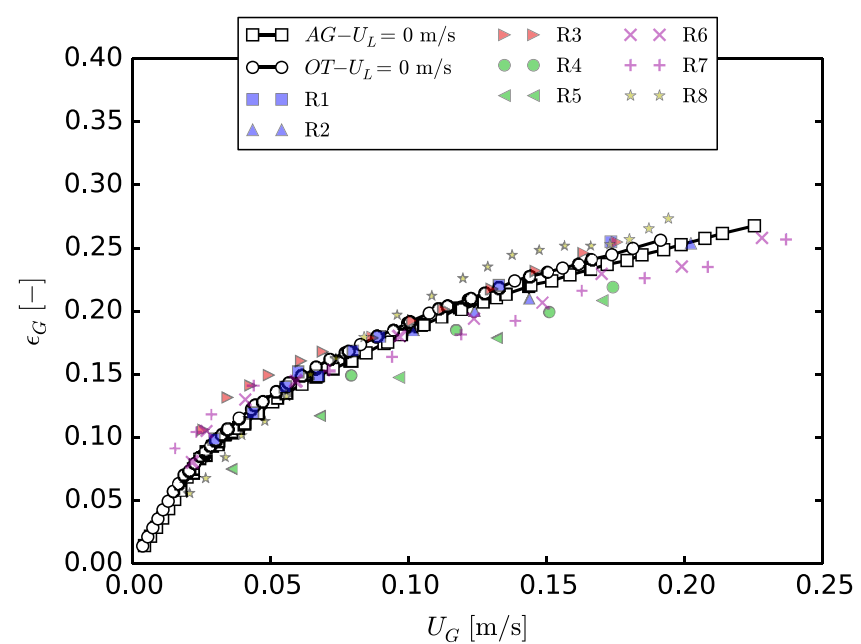

Fig. 5. Gas holdup: comparison with experimental data from the literature.

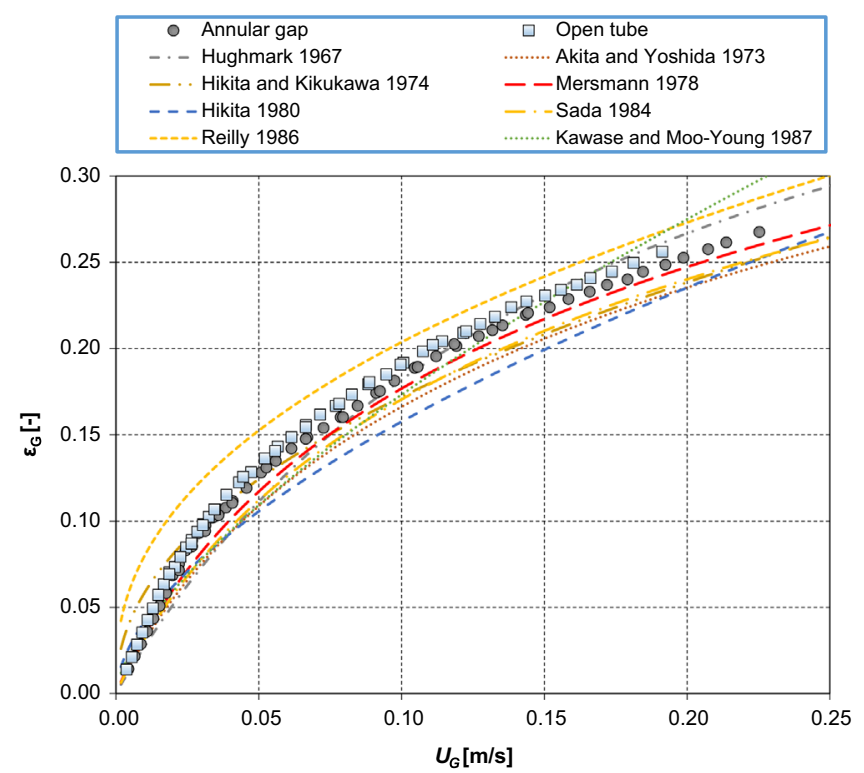

Fig. 6. Gas holdup: comparison with correlations from the literature.

- Reilly et al. (1986):

$\varepsilon_{G}=296 \cdot U_{G}^{0.44} \rho_{L}^{-0.98} \sigma^{-0.16} \rho_{G}^{0.19}+0.009$

- Kawase and Moo-Young (1987):

$\varepsilon_{G}=1.07 \cdot n^{2 / 3}\left(\frac{U_{G}^{2}}{g d_{c}}\right)^{1 / 3}$
The reader should refer to Appendix B for a detailed discussion of these correlations and their range of applicability. The OT configuration is well predicted for both low and high air superficial velocities by the correlation of Hughmark (1967). In contrast, the AG configuration is well predicted by Mashelkar (1970) correlation. The correlation of Reilly et al. (1986) gives a similar trend to the experimental data; however, a constant shift in holdup is observed. The correlation of Kawase and Moo-Young (1987) underestimates the data in the homogeneous regime and overestimate the data in the heterogeneous regime. The correlation of Hikita and Kikukawa (1974) exhibits the opposite behavior. All of the other correlations underestimate the data in all of the flow regimes.

\subsubsection{Proposed gas holdup correlation}

The correlations from the literature have low accuracy in predicting the holdup throughout the operating range; therefore, a new correlation is proposed. The relationship between the gas holdup and the physical properties of the system may be written as a function of the following parameters:

$\varepsilon_{G}=f\left(g, U_{G}, d_{e q}, \mu_{L}, \rho_{L}-\rho_{G}, g\right)$

This equation can be transformed through the dimensional analysis:

$\varphi=f\left(\frac{U_{G} \mu_{L}}{\sigma}, \frac{g \mu_{L}^{4}}{\left(\rho_{L}-\rho_{G}\right) \sigma^{3}}\right)=f(C a, M o)$

Different formulations can be used for the function $f$, and, in this paper, the same expression proposed by Akita and Yoshida (1973) is used:

$\frac{\varepsilon_{G}}{\left(1-\varepsilon_{G}\right)^{n}}=k_{1} M o^{k_{2}} C a^{k_{3}}$

Holding the liquid properties constant, the $M o^{k 2}$ term becomes constant:

$\frac{\varepsilon_{G}}{\left(1-\varepsilon_{G}\right)^{n}}=k_{1}^{*} C a^{k_{3}}$

which can be rewritten as follows:

$\ln \left(\frac{\varepsilon_{G}}{\left(1-\varepsilon_{G}\right)^{n}}\right)=k_{3} \ln (C a)+\ln \left(k_{1}^{*}\right)$

which is equivalent to

$y=m x+q$

where $k_{3}=\mathrm{m}, \ln (\mathrm{Ca})=x$ and $\ln \left(k_{1}{ }^{*}\right)=q$. The results of the analysis can be found in Table 2. Then, the exponent $\mathrm{n}$ is selected as the one that better fits the experimental data. For the AG configuration, $n=4$, such as in Akita and Yoshida. For the OT configuration, $n=4$ gives unsatisfactory results, and $n=3.7$ is selected. The results are displayed in Fig. 7: the proposed correlation matches the data fairly well compared to the previous correlations in the literature. Future study should expand the correlation for other column design as well as for considering the counter-current operation mode. 
Table 2

Parameters in the proposed correlations.

\begin{tabular}{lllll}
\hline Configuration & $R^{2}$ & $k_{3}$ & $k_{1}^{*}$ & Correlation \\
\hline Annular gap & 0.9958 & 0.9966 & 329.31 & $\frac{\varepsilon_{G}}{\left(1-\varepsilon_{G}\right)^{n}}=329.31 \mathrm{Ca}^{0.997}$ \\
Open tube & 0.9976 & 0.9818 & 321.69 & $\frac{\varepsilon_{G}}{\left(1-\varepsilon_{G}\right)^{n}}=321.69 \mathrm{Ca}^{0.9818}$ \\
\hline
\end{tabular}

a

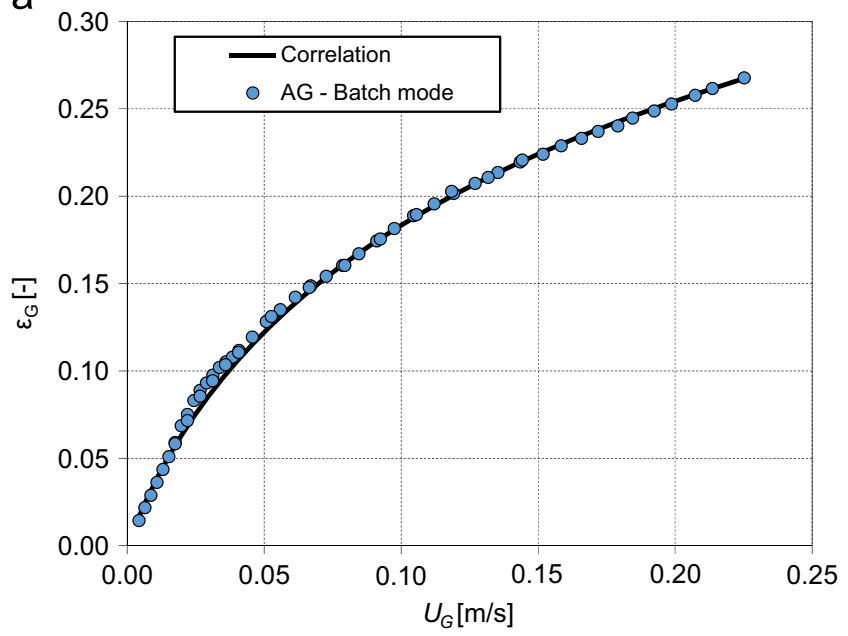

Annular Gap

b

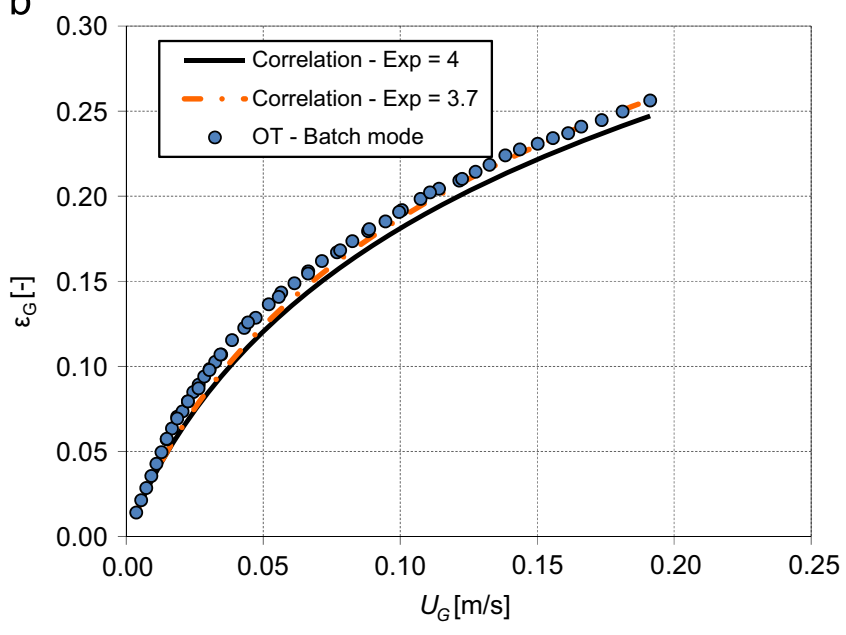

Open Tube

Fig. 7. Proposed correlations for the gas holdup.

\subsection{Flow regime transition analysis}

Herein we discuss the influence of the liquid velocity and column design on the regime transition. At first the results of the flow regime transition analysis are presented and a comparison with the typical value in the literature is given. At second, we analyze the influence of the liquid velocity on the flow regime transition and, at third, we compare the open tube and the annular gap configuration. Finally, we compare our data with correlations from the literature.

\subsubsection{Flow regime transition results}

The results of the first method are presented in Figs. 8 and 10 for the AG and the OT configuration, respectively. The results of the second method are presented in Figs. 9 and 11 for the AG and the OT configuration, respectively. The value of the transitional gas velocity is in agreement between the two methods, and, following the proposal

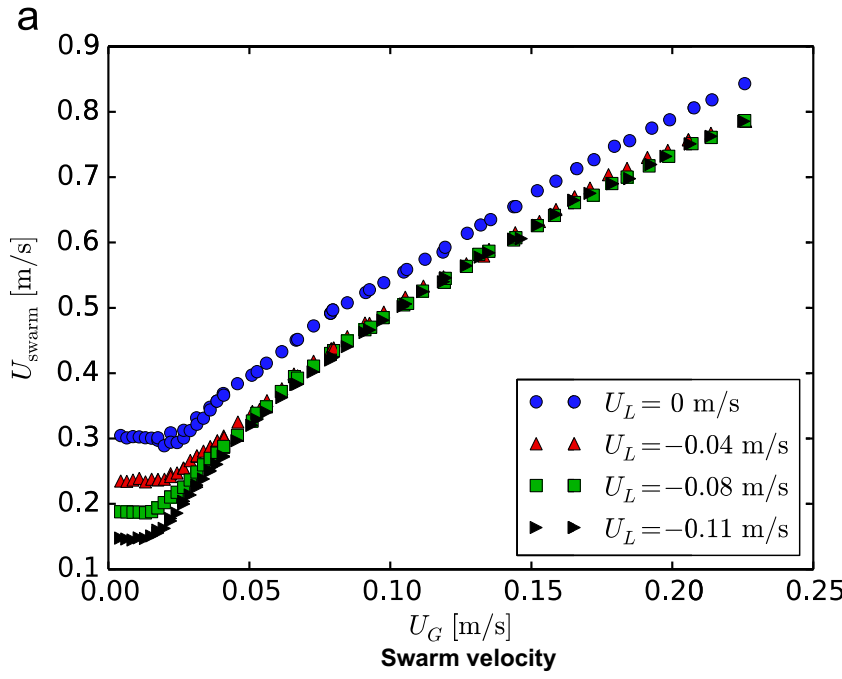

b

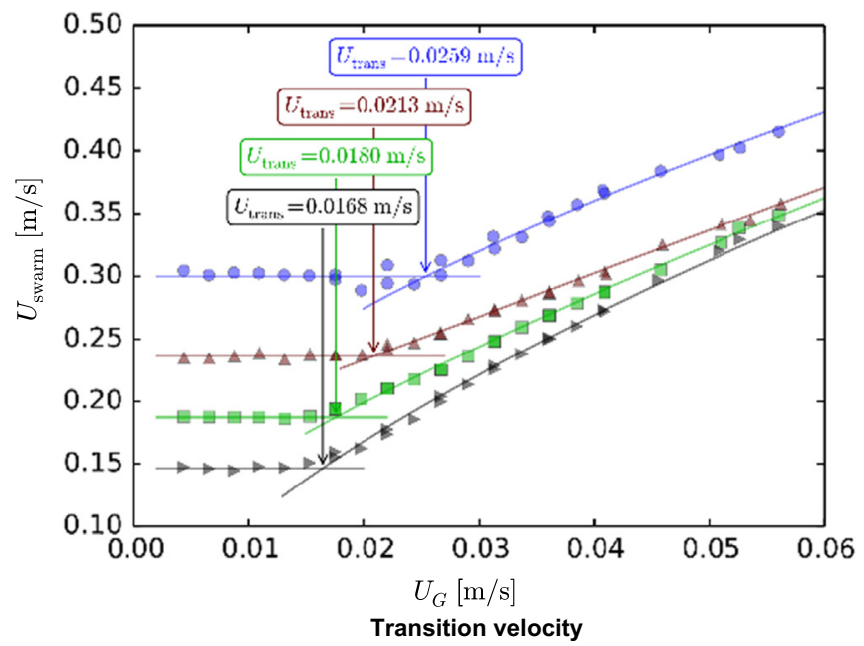

Fig. 8. AG configuration: swarm velocity analysis.

of Ribeiro and Mewes (2007) and Besagni and Inzoli (2015), the transition points have been evaluated as the mean of the two values, and the results for the holdup and gas velocity are presented in Fig. 12.

The flow regime transitions, depending on the liquid velocity and the column design, lie in the range between $0.0266 \mathrm{~m} / \mathrm{s}$ and $0.0110 \mathrm{~m} / \mathrm{s}$. The typical values of $U_{\text {trans }}$ found in the literature for the air-water systems in bubble columns of diameter higher than $0.15 \mathrm{~m}$ range between 0.01 and $0.08 \mathrm{~m} / \mathrm{s}$ at ambient operating conditions (Dargar and Macchi, 2006; Hur et al., 2013; Krishna et al., 1991; Letzel et al., 1999; Reilly et al., 1994; Ruzicka et al., 2001; Schumpe and Grund, 1986; Urseanu, 2000; Wilkinson et al., 1992; Zahradnik et al., 1997). The value depends mainly on the distributor type. Single and multiple nozzles or perforated plate distributors with hole diameter greater than $1 \mathrm{~mm}$ ("coarse" distributors) usually lead to an early regime transition, while "fine" distributors such as porous plates (Al-Oufi et al., 2010; Al-Oufi et al., 2011) or needles (Mudde et al., 2009) can maintain a stable homogeneous regime at higher gas flow rates (i.e., Mudde et al. reported homogeneous regime up to an holdup equal to 0.55). The distributor considered in this study is of the "coarse" type, and the values of $U_{\text {trans }}$ suggest an early destabilization of the homogenous regime.

A brief comparison with some of the previous studies is presented in Table 3 . The values in the present study are in very good agreement with the studies of Dargar and Macchi, (2006) and Rollbusch et al. (2015). Ribeiro and Mewes (2007), Zahradnik et al. 

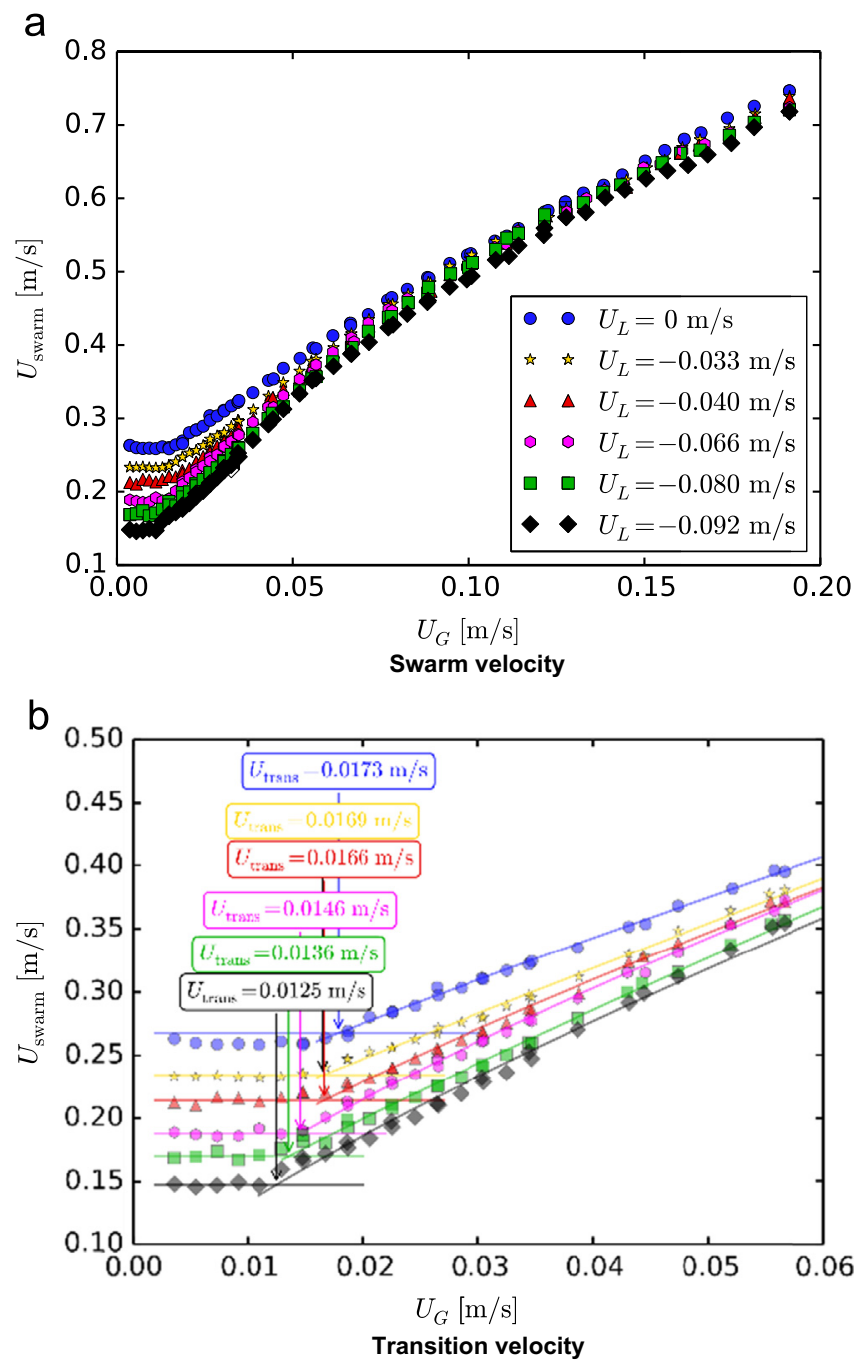

Fig. 9. OT configuration: swarm velocity analysis.

(1997) and Al-Oufi et al. (2010, 2011) reported a flow regime transition for a larger holdup than our value. Probably, this is due to the air distribution at the inlet (i.e., the porous sparger in Al-Oufi et al. or perforated plate sparger with $d_{\text {hole }}<1 \mathrm{~mm}$ ). The transition holdups measured by Krishna et al. (2000), Urseanu (2000) and Letzel et al. (1999) are around 10\% higher than those obtained in this study. This point was also found and discussed by Rollbusch et al. (2015).

It is worth noting that, in the AG configuration, Besagni and Inzoli (2016) observed a poly-dispersed bubble size distribution (accordingly with the change of sign in the lift force) and the appearance of cap-bubbles also in the homogeneous regime. The cap-bubbles raised the column at a higher velocity compared to the other bubbles and generated break-up phenomena in their path. The poly-dispersed nature of the bubble size distribution as well as the presence of the cap bubbles contribute to the early destabilization of the homogeneous regime (Lucas et al., 2003, 2006).

\subsubsection{Influence of the liquid velocity}

For both the AG and the OT configuration, the transition velocity decreases while increasing the liquid velocity (Fig. 12): the counter-current operating conditions destabilize the homogeneous flow. The counter-current liquid slows the bubbles, increasing the holdup, the local void fraction and the bubble mean diameter (refer to the optical probe results): thus, for the same superficial gas velocity, the mean distance between the bubbles decreases, and therefore, coalescence phenomena may occur more easily because of the expected increase in bubble collisions. The higher void fraction is clear from the holdup measurement (Section 3.1) and optical probe data (Section 3.3).

It is particularly interesting that the relationship between the superficial water velocity and the transitional velocity is linear for the AG configuration $\left(R^{2}=0.9994\right)$ :

$U_{G, \text { trans }}=-0.0939 U_{L}+0.0264$

and the OT configuration (OT: $R^{2}=0.9334$ ):

$U_{G, \text { trans }}=-0.0673 U_{L}+0.0187$

This result may be seen as a consequence of the linear increase of the holdup in the homogeneous regime. In the literature, Otake et al. (1981) observed an increase in the holdup and earlier regime transitions as the counter-current liquid flow rate increased in a small pipe of diameter $0.05 \mathrm{~m}$. Their analysis covered gas superficial velocities up to $0.0824 \mathrm{~m} / \mathrm{s}$ and liquid superficial velocities up to $-0.15 \mathrm{~m} / \mathrm{s}$. Similar conclusions were drawn by Yamaguchi and Yamazaki (1982) for small pipes with diameters of $0.04 \mathrm{~m}$ and $0.08 \mathrm{~m}$, with gas superficial velocities up to $-1 \mathrm{~m} / \mathrm{s}$. In contrast, Akita and Yoshida (1973) observed that the liquid flow rate had no influence in a large pipe with diameter $0.152 \mathrm{~m}$ at gas superficial velocities up to $0.032 \mathrm{~m} / \mathrm{s}$ and liquid superficial velocities up to $-0.04 \mathrm{~m} / \mathrm{s}$. The latter is in disagreement with what we observed in the homogeneous regime, while the former suggests an influence of liquid flow rate at gas superficial velocities higher than $0.06 \mathrm{~m} / \mathrm{s}$. Our results, considering the literature, may support the idea of a correlation between the superficial liquid velocity and the transitional velocity.

\subsubsection{Influence of the internals}

In the OT configuration, the flow regime transition begins earlier (Fig. 12). This behavior is difficult to explain. A possible cause may be the distributor: in the OT configuration, the distributor causes higher bubble coalescence in the region upstream of itself due to the absence of the internals. Al-Oufi et al. (2010, 2011) found that the annular gap-configuration destabilize the homogenous flow, and the flow transition appear at higher superficial gas velocity (i.e., $U_{\text {trans }}$ moves from $0.048 \mathrm{~m} / \mathrm{s}$ to 0.047 and $0.026 \mathrm{~m} / \mathrm{s}$, depending on the annulus and, accordingly, $\varepsilon_{\text {trans }}$ moves from 0.26 to 0.15 ): this is in disagreement with our finding and the most probable cause is the distributor used (Al-Oufi et al. used a porous sparger). $U_{\text {trans }}$ for the annular gap configuration of Al-Oufi et al. is in agreement with our data, but $\varepsilon_{\text {trans }}$ is higher. This is probably caused by the porous sparger distributor, which is known for stabilizing the homogeneous flow also at higher void fraction. In the literature, we can also refer to studies concerning variation in the column diameter. Sarrafi et al. (1999) found that transition velocity increases with increasing column diameter. However, it becomes independent of column diameter beyond $0.15 \mathrm{~m}$. Ohki and Inoue (1970) found that transition velocity increases with increasing column diameter in the range of 0.04$0.16 \mathrm{~m}$. Ruzicka et al. (2001) utilized their own gas holdup data from three different column diameters $(0.14,0.29$, and $0.4 \mathrm{~m})$ to calculate transition velocity. They found that an increase in column diameter reduced transition velocity. Their results are consistent with the observations of Zahradnik et al. (1997).

\subsubsection{Comparison with correlation from the literature}

We compare our experimental data with literature correlations. One of the first correlations proposed is by Wilkinson et al. (1992):

$U_{\text {trans }}=0.5 U_{b, \text { small }} \exp \left(-193 \rho_{G}^{-0.61} \mu_{L}^{0.5} \sigma^{0.11}\right)$

with

$U_{b, \text { small }}=2.25 \frac{\sigma}{\mu_{L}}\left(\frac{\sigma^{3} \rho_{L}}{g \mu_{L}^{4}}\right)^{-0.273}\left(\frac{\rho_{L}}{\rho_{G}}\right)^{0.03}$ 
a

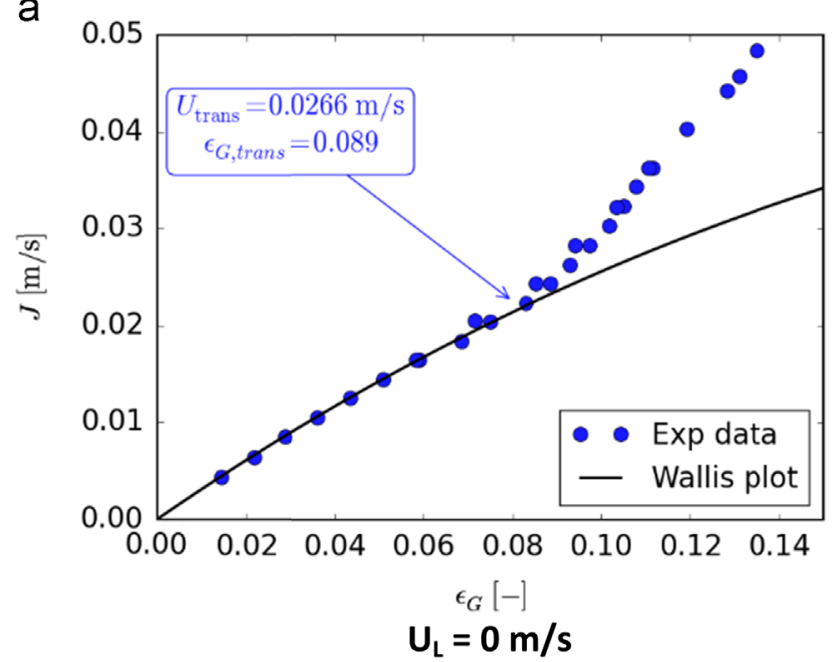

C

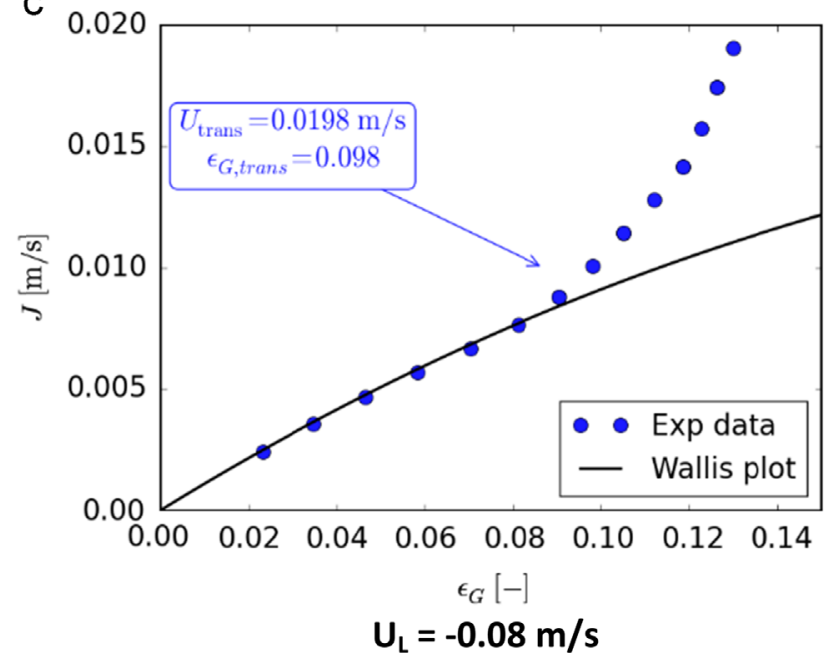

b

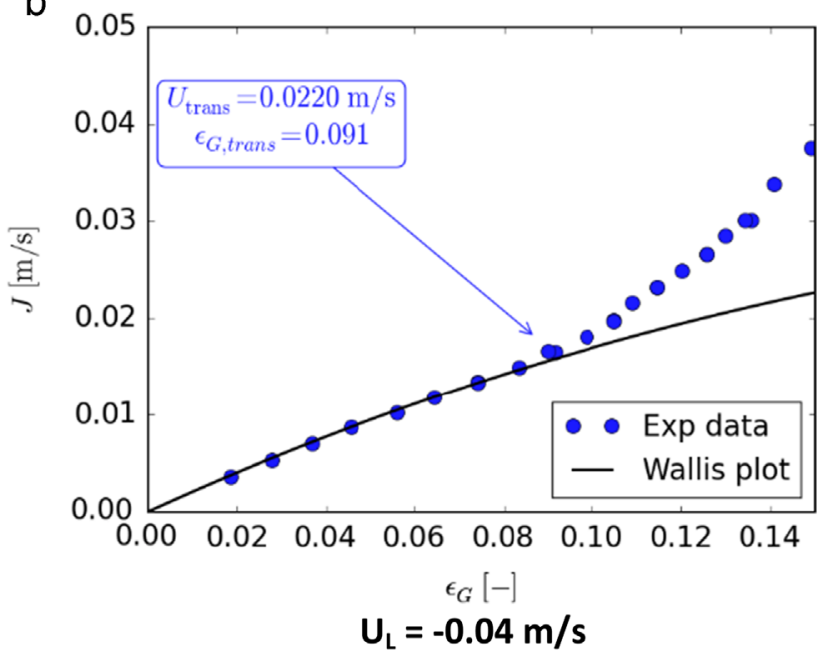

d

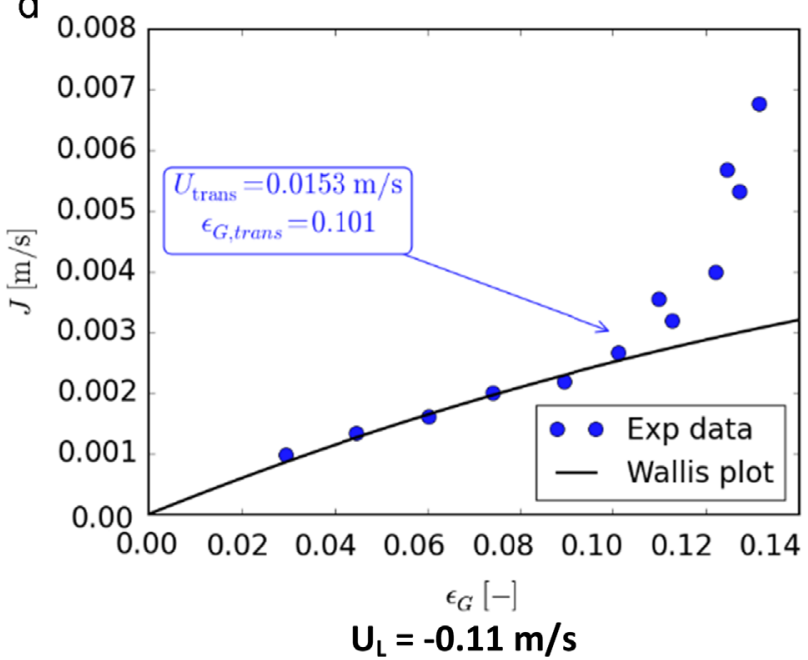

Fig. 10. AG configuration: Wallis plot analysis.

Another correlation is proposed by Reilly et al. (1994) and reads as follows:

$U_{\text {trans }}=\frac{\rho_{L}}{\rho_{G}}\left(1-\varepsilon_{G, \text { trans }}\right)\left(\frac{B^{*}}{A^{*}}\right)^{1.5}$

with the holdup at the transition

$\varepsilon_{G, \text { trans }}=0.59 B^{* 1.5}\left(\frac{\sigma^{0.12} \rho_{G}^{0.96}}{\rho_{L}}\right)^{0.5}$

and

$A^{*}=2.81 \rho_{L} \rho_{G}^{0.96} \sigma^{-0.12}$

For water as the liquid phase $B^{*}=3.75$ Comparisons of $U_{\text {trans }}$ and $\varepsilon_{G, \text { trans }}$ from the experimental investigation and these correlations are given in Table 4. Eq. (30) largely underestimates the transition gas velocity. This observation was also made by Letzel et al. (1999), who also compared their results with the correlation of Reilly et al. (1994), which provide better agreement. In contrast, Eq. (32) gives values for $U_{\text {trans }}$ and $\varepsilon_{G, \text { trans }}$ in agreement with the experimental data.

The reader should also refer to the discussion of Besagni and Inzoli (2016) concerning the use of the stability analysis to predict the regime transition.

\subsection{Optical probe measurements}

The data in the midpoint position of the annular gap configuration have been discussed in Besagni et al. (2015); therefore, this section is devoted to the OT configuration only. In the OT configuration, both midpoint and radial measurements have been acquired.

\subsubsection{Midpoint measurements}

Midpoint measurements have been acquired by placing the optical probe in the center of the column (Fig. 2). The local void fraction (Fig. 13a) increases with superficial air velocity, as expected. The local void fraction measured with the optical probe also followed expected trends when compared with global values (Fig. 13a). In the homogeneous regime, the local holdups at the center of the column were comparable to global values, where radial profiles for these conditions were shown to be flatter compared to the heterogeneous flow regime. After the flow regime transition, the probe measurements are higher than the holdup, because of the center peaked void fraction profiles (Section 3.3.1). The same behavior was also observed by Pjontek et al. (2014). Fig. 13a also displays the influence of the superficial liquid velocity on the local void fraction: the local holdup decreases with increasing superficial water velocity. This result is in agreement with the holdup measurements and occurs because bubbles move in a non-stagnant surrounding liquid, which is forced to move 
a

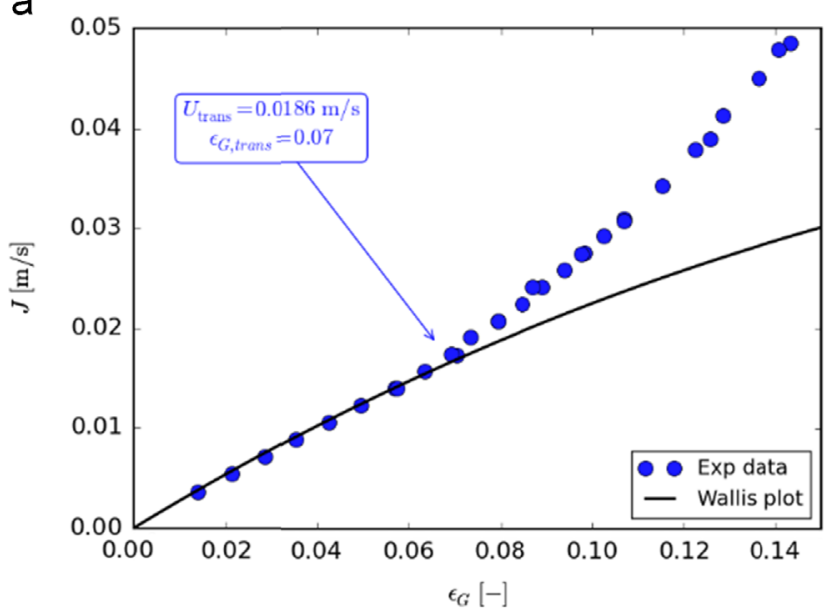

$\mathrm{U}_{\mathrm{L}}=\mathbf{0} \mathrm{m} / \mathrm{s}$

C

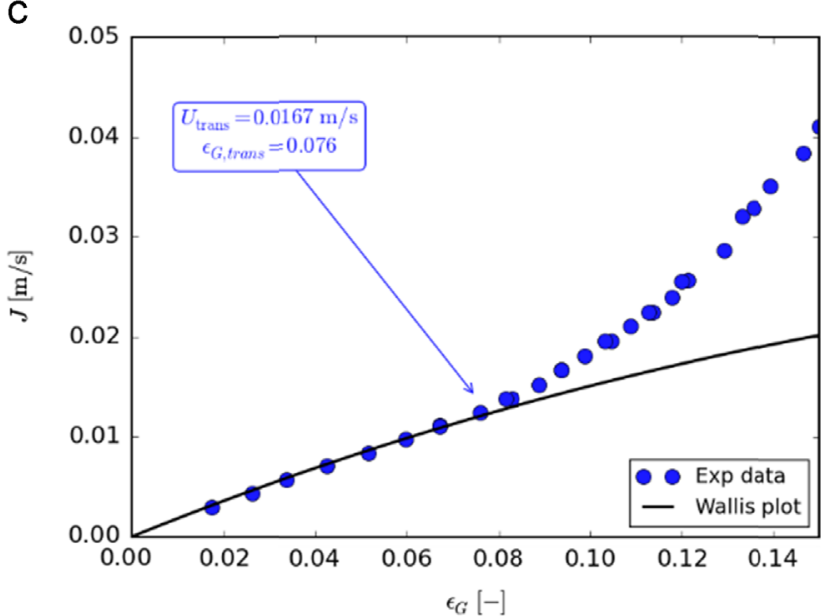

$U_{\mathrm{L}}=-0.04 \mathrm{~m} / \mathrm{s}$

e

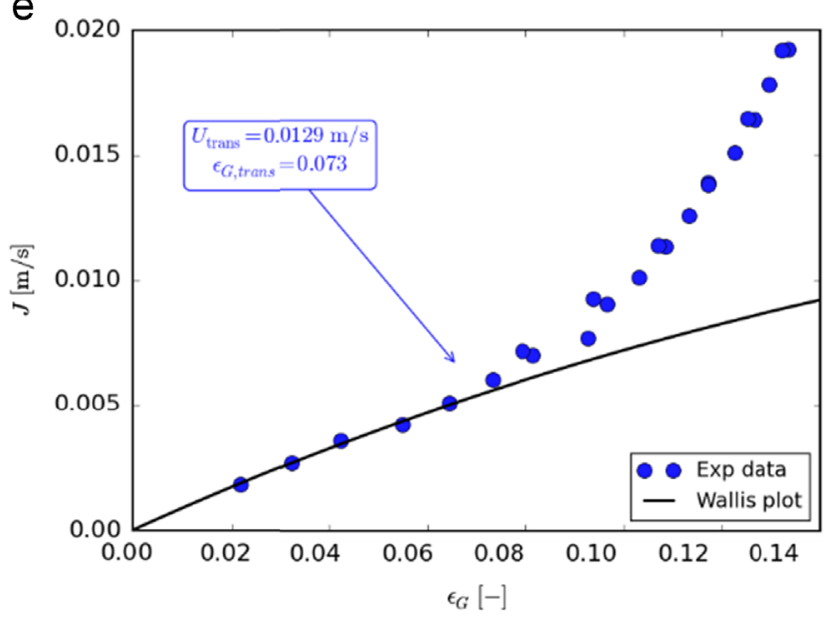

$U_{L}=-0.08 \mathrm{~m} / \mathrm{s}$ b

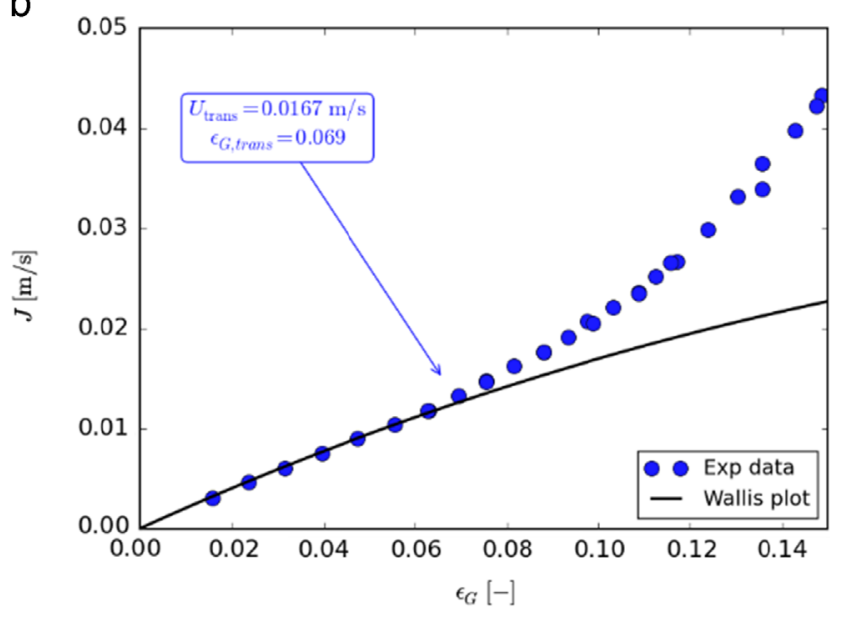

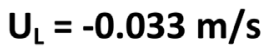

d

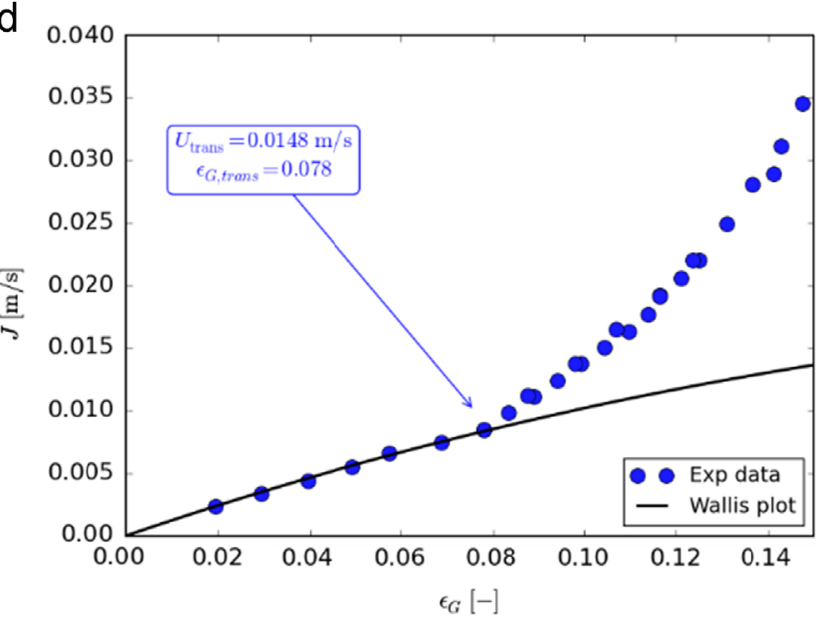

$U_{L}=-0.066 \mathrm{~m} / \mathrm{s}$

$f$

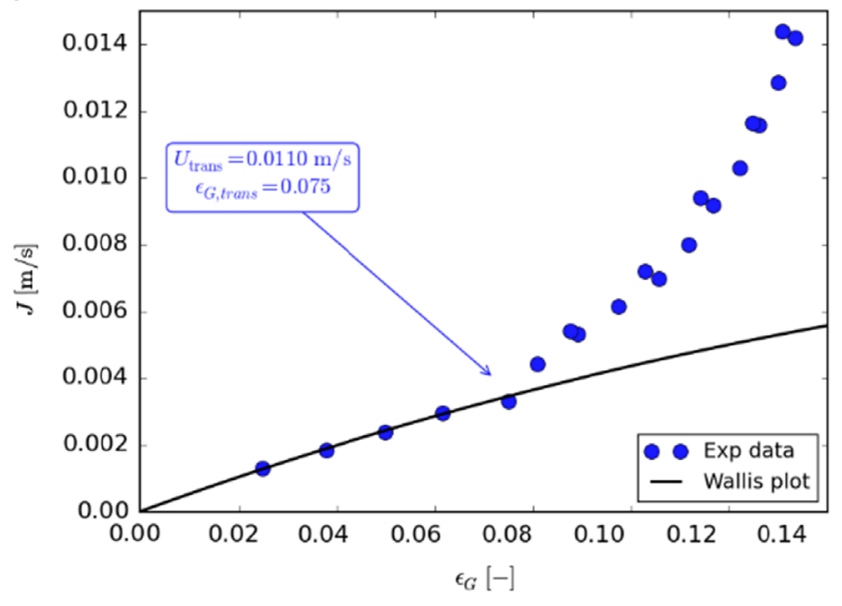

$U_{L}=-0.092 \mathrm{~m} / \mathrm{s}$

Fig. 11. OT configuration: Wallis plot analysis.

downward. This point is also noticed in the radial measurements (Section 3.3.2). Fig. 13b presents the relationship between the local void fraction and the holdup: the relation is linear in the homogeneous regime also in the counter-current operation. It is interesting that, after the flow regime transition, the local data become more scattered. This behavior suggests center peaked profiles, which are also confirmed by the radial measurements. The relation between local void fraction, for the batch mode and the holdup is the following $\left(R^{2}=0.9981\right)$.

$\varepsilon_{G, \text { Local }}=0.4254 \varepsilon_{G}^{2}+1.2485 \varepsilon_{G}$ 


\section{a}

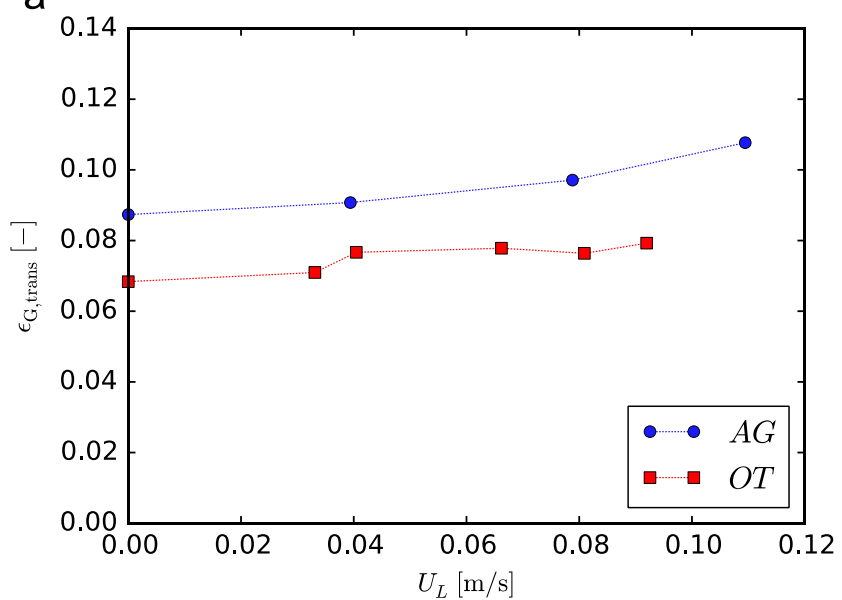

"AG"

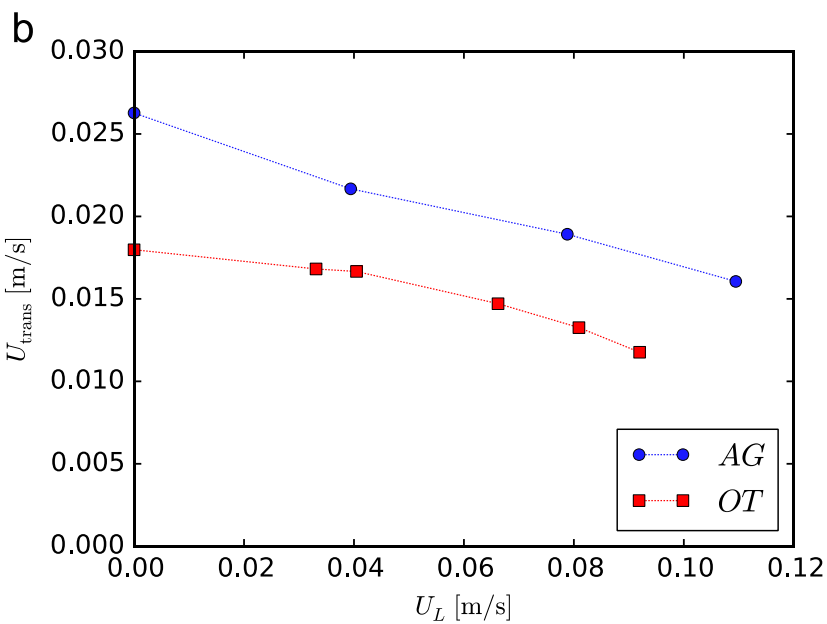

"OT"

Fig. 12. Transition holdup and gas velocity.

Table 3

Flow regime transition comparison with data from the literature.

\begin{tabular}{|c|c|c|c|c|}
\hline Refs. & $d_{c}[\mathrm{~m}]$ & Sparger type & $\varepsilon_{G, \text { trans }}$ [dimensionless] & $U_{\text {trans }}[\mathrm{m} / \mathrm{s}]$ \\
\hline This study - OT & 0.24 & Pipe sparger $d_{\text {hole }}=3.5 \mathrm{~mm}$ & 0.0683 & 0.0179 \\
\hline This study - AG & 0.24 & Pipe sparger $d_{\text {hole }}=3.5 \mathrm{~mm}$ & 0.0874 & 0.0263 \\
\hline (Zahradnik et al., 1997) & 0.15 & Perforated plate $d_{\text {hole }}=0.5 \mathrm{~mm}$ & 0.21 & 0.04 \\
\hline (Ribeiro and Mewes, 2007) & 0.12 & Perforated plate $d_{\text {hole }}=0.7 \mathrm{~mm}$ & 0.35 & 0.0405 \\
\hline (Rollbusch et al., 2015) & 0.16 & Perforated plate $d_{\text {hole }}=1 \mathrm{~mm}$ & 0.068 & 0.03 \\
\hline (Urseanu, 2000) & 0.051 & Perforated plate $d_{\text {hole }}=0.5 \mathrm{~mm}$ & 0.098 & 0.019 \\
\hline (Urseanu, 2000) & 0.15 & Perforated plate $d_{\text {hole }}=0.5 \mathrm{~mm}$ & 0.127 & 0.027 \\
\hline (Krishna et al., 2000) & 0.15 & Sieve plate $d_{\text {hole }}=0.5 \mathrm{~mm}$ & 0.11 & 0.025 \\
\hline (Letzel et al., 1999) & 0.15 & Perforated plate $d_{\text {hole }}=0.1 \mathrm{~mm}$ & 0.13 & 0.027 \\
\hline (Dargar and Macchi, 2006) & 0.152 & Perforated plate $d_{\text {hole }}=0.8 \mathrm{~mm}$ & 0.09 & 0.028 \\
\hline (Al-Oufi et al., 2011) - AG & 0.102 & Porous sparger & 0.26 & 0.048 \\
\hline (Al-Oufi et al., 2011) - OT & 0.102 & Porous sparger & $0.25-0.15^{\mathrm{a}}$ & $0.047-0.026^{a}$ \\
\hline
\end{tabular}

a Depending on the annular gap.

Table 4

Flow regime transition comparison with correlations from the literature.

\begin{tabular}{lllll}
\hline & $\begin{array}{l}\text { Exp. annu- } \\
\text { lar gap }\end{array}$ & $\begin{array}{l}\text { Exp. } \\
\text { open } \\
\text { tube }\end{array}$ & $\begin{array}{l}\text { (Wilkinson et } \\
\text { al., 1992) }\end{array}$ & $\begin{array}{l}\text { (Reilly et } \\
\text { al., 1994) }\end{array}$ \\
\hline$U_{\text {trans }}[\mathrm{m} / \mathrm{s}]$ & 0.0263 & 0.0179 & 0.00198 & 0.0289 \\
$\varepsilon_{G, \text { trans }}[$ dimensionless] & 0.0874 & 0.0683 & 0.0077 & 0.0077 \\
\hline
\end{tabular}

These data, coupled with the radial measurements (Section 3.3.2) may be used - in future studies-for providing detailed information on the local void fraction profiles and for developing a Drift Flux model (Zuber and Findlay, 1965) of the large-diameter bubble column.

The comparisons between global and local measurements in the midpoint provided an additional method to establish the bubble flow regime, as also performed by Pjontek et al. (2014). Bubble flow regime detection using local measurements has also been demonstrated by Shiea et al. (2013). To better investigate the flow regime transitions, the global and the local swarm velocity are compared in Fig. 14a. The transitional superficial gas velocity is similar, but the local swarm velocity starts increasing for lower gas velocity (Fig. 14b). This is probably induced by the large bubbles that moves toward the center of the pipe and rise the column at higher velocity (Lucas et al., 2003).

The bubble vertical velocity (Fig. 15a) increases with superficial air velocity: the relation is linear in the homogeneous regime, followed by a change in slope due to the regime transition. This relation provide an insight in the holdup curve (Fig. 3b): applying the mass conservation to the gas phase, the holdup is given by $\varepsilon_{G}=U_{G} / u_{G}$ ( $u_{g}$ refers to the mean gas phase rise velocity). Theoretically, if all the bubbles would travel at their terminal velocity, the holdup would increase linearly with the gas flow rate. However, the coupling between the phases causes deviations from the linearity (Ruzicka et al., 2003). In the homogeneous regime, the hindrance reduces the bubble velocity, thus increasing holdup, whereas, in the heterogeneous regime, the circulations enhance the bubble velocity resulting in a decrease of the holdup. The local values of the bubble rise velocities are, thus, strictly related to the holdup. This relation is further investigated in Fig. 15b, which correlates the local parameters: the relationship between the local void fraction and the bubble rise velocity appears linear (Fig. 15b) till the regime transition, but the slope starts increasing after the regime transition. Considering that these measurements were taken in the midpoint position, this result supports the theory of larger bubbles mowing toward the center of the pipe (Lucas et al., 2003).

\subsubsection{Radial measurements}

Figs. 16-18 represent the radial optical probe measurements for the local void fraction, bubble rise velocity and bubble diameter. Both the batch $\left(U_{L}=0 \mathrm{~m} / \mathrm{s}\right)$ and counter-current $\left(U_{L}=-0.008 \mathrm{~m} / \mathrm{s}\right)$ mode were investigated.

Local void fraction up profiles may be center peaked, wall peaked or flat, depending on $U_{G}, U_{L}$, the column design, the 
sparger design, the nature of the gas-liquid system and the operating conditions. During the past decades, a large number of experimental measurements of void fraction have been reported

a

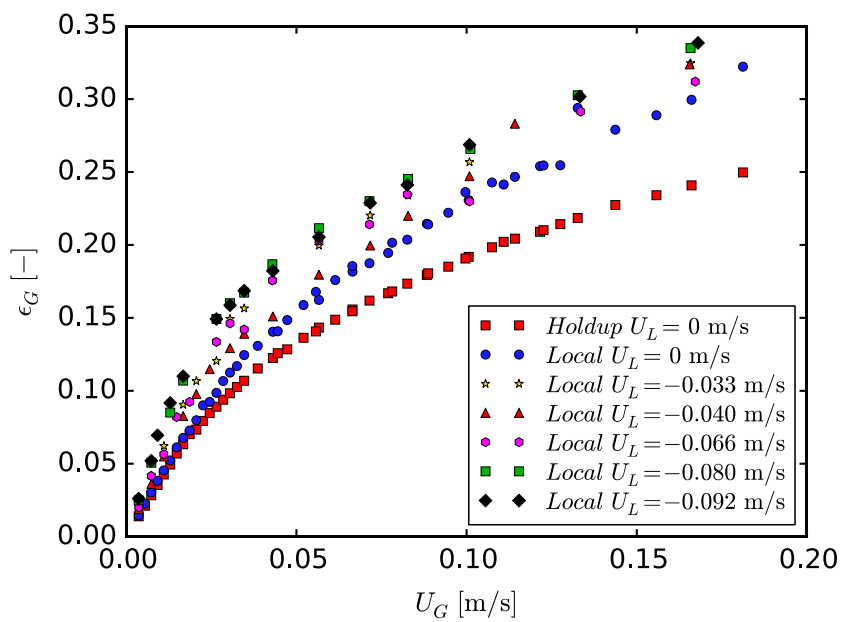

Comparison

b

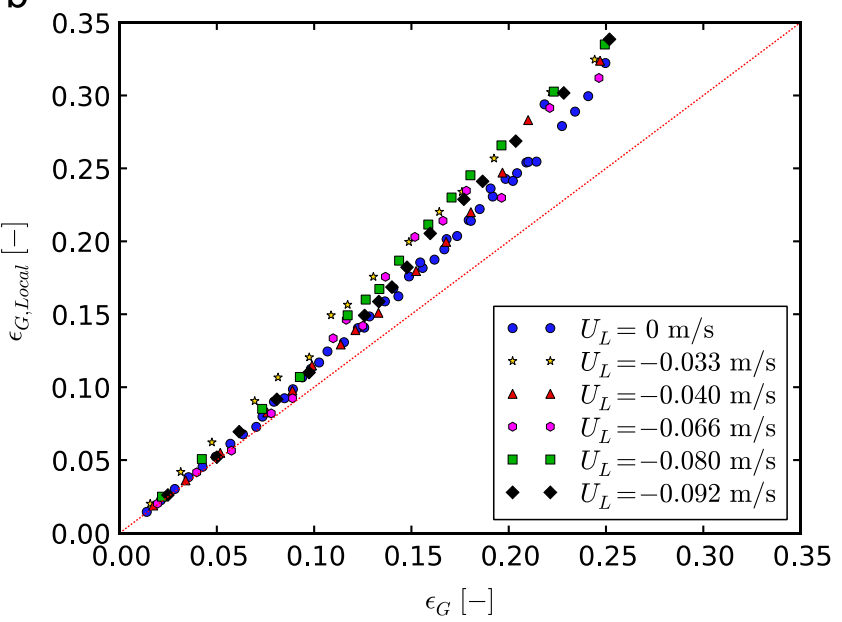

Parity plot

Fig. 13. Midpoint optical probe measurements: holdup and local void fraction comparison.

\section{a}

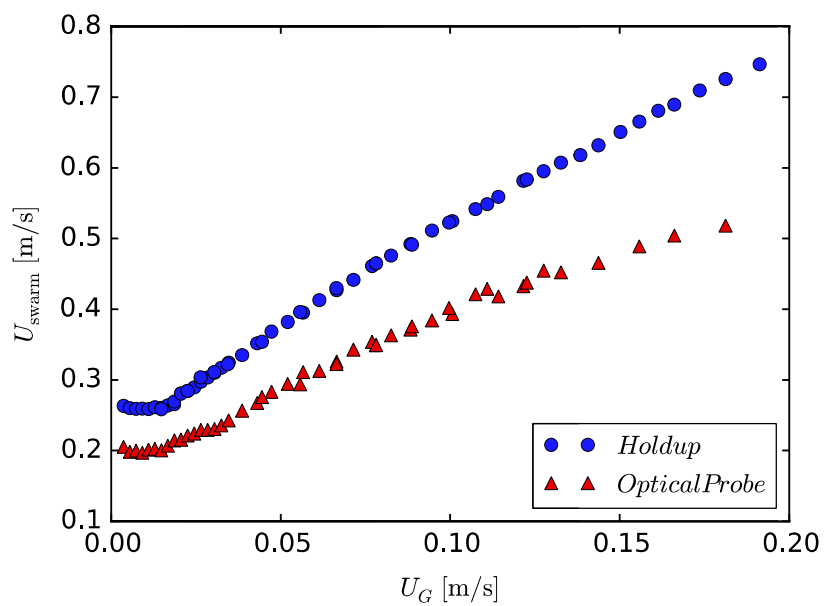

Swarm velocity plot by using a variety of techniques, as reviewed by Joshi et al. (1998). In the present case, the local void fraction profiles are center peaked (Fig. 16a and b). This may appear surprisingly: usually, in the homogeneous regime, the void fraction profiles are more or less flat. This behavior may be caused by the sparger with the large openings, which produces a poly-dispersed flow in the column (Besagni and Inzoli, 2016). Increased gas flow rates resulted in overall higher void fractions and greater profile curvature from the column wall to the center, particularly after the flow regime transition. The formation of larger bubbles at higher gas flow rates (Urseanu, 2000) led to increased curvature of the radial profiles, where maximum local gas holdups occurred at the center of the column. The existence of a pronounced radial holdup profile, which generates strong liquid recirculation, is a well-known characteristic of the heterogeneous regime. The center peaked void fraction profiles induced the higher midpoint void fraction measurements compared with the global holdup values (Fig. 13a). The local void fractions $\varepsilon_{G \text {,Local }}$ obtained with the optical probe (Fig. 16) were compared to global holdups by integrating the radial measurements over the column cross sectional area:

$<\varepsilon_{G}>=\frac{1}{\pi R_{c}^{2}} \int_{0}^{R_{c}} \varepsilon_{G, \text { Local }} 2 \pi r d r$

where $R_{c}$ is the radius of the column. Table 5 shows that the integrated local measurements, with the exception of one countercurrent case, within $\pm 20 \%$ of global measurements are in agreement with the literature (Pjontek et al., 2014). This result is also in agreement with Barrau et al. (1999), reporting the worst performance of the optical probes at low gas fractions. The error may also derive from the pressure gradient along the column, which causes an axial profile of the local void fraction. In this case, an increase in pressure of approximately 0.3 bar is expected from the free surface to the bottom of the column.

Concerning the bubble vertical velocity, $u_{b}$, an increase in air superficial velocity leads to an increase in bubble vertical velocity, as expected (Fig. 17a). However, the increase in velocity is limited in the homogeneous regime, with the exception of $U_{G}=0.0187 \mathrm{~m} /$ s. This result may support that the flow regime transition begins near this point: above the transition velocity, the bubble coalescence increases the average rise velocity and reduces gas residence time in the column, hence decreasing the gas holdup versus gas velocity slope (Fig. 3). In counter-current-mode, the local void fraction increases (Fig. 16b), which is explained by the effect of the liquid flow, slowing down the rise of the bubbles (Fig. 17b).

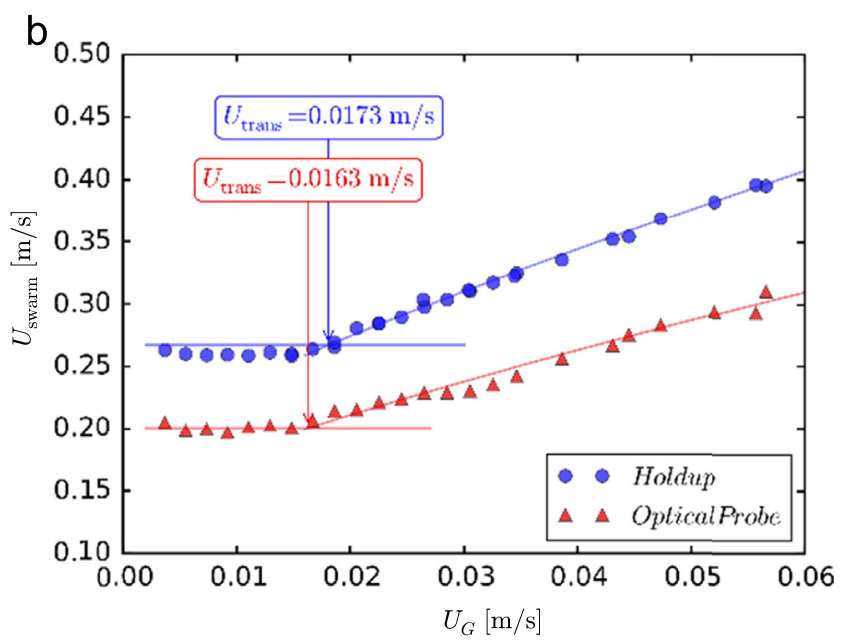

Focus on the transition point

Fig. 14. Midpoint optical probe measurements: global and local swarm velocities. 


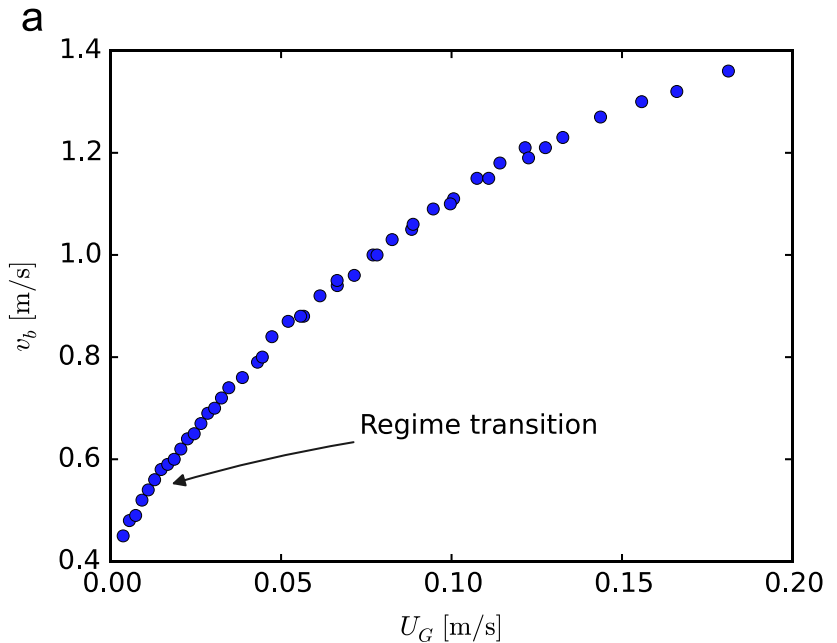

Relation between $u_{b}$ and $U_{G}$

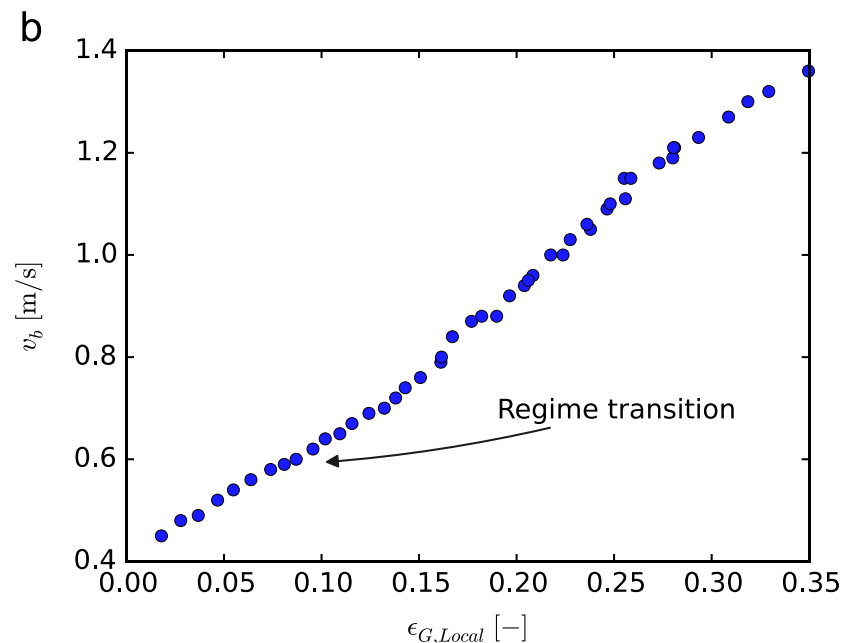

Relation between $u_{b}$ and $\varepsilon_{G, \text { Local }}$

Fig. 15. Midpoint optical probe measurements: bubble rise velocity.

a

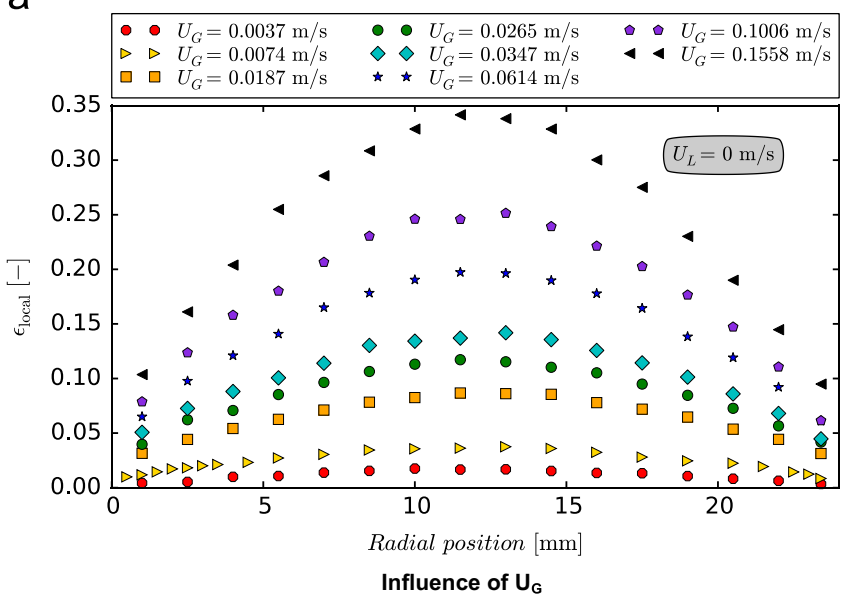

b

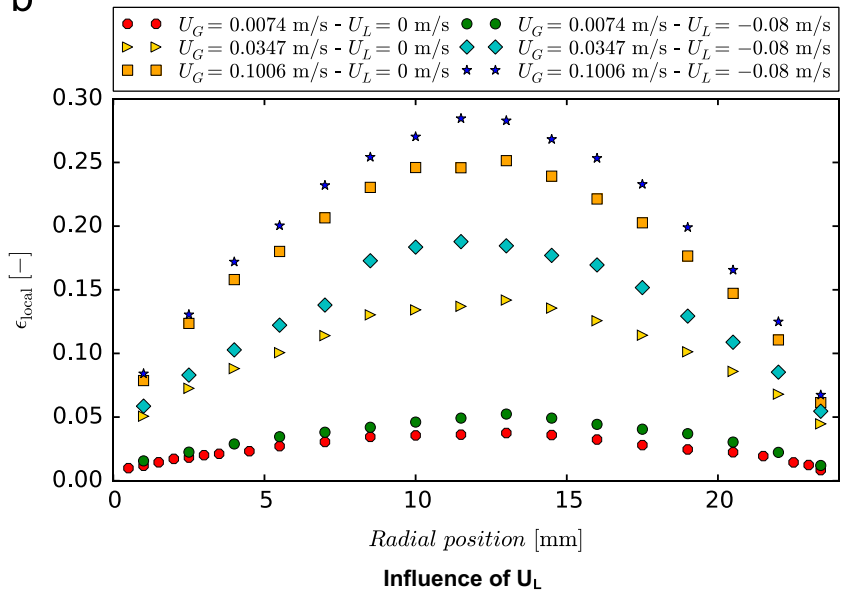

Fig. 16. Radial optical probe measurements: local void fraction.

Fig. 18 presents the bubble diameter radial distribution as a function of the superficial gas velocity (Fig. 18a) and superficial water velocity (Fig. 18b). Eq. (14) was used along with a mean aspect ratio of 0.6. Considering Fig. 18a, the bubble mean diameter is almost constant in the cross section of the pipes, and there are no remarkable differences between the cases $U_{G}=0.0037$ and $U_{G}=0.0074 \mathrm{~m} / \mathrm{s}$, both below the flow regime transition. However, at $U_{G}=0.187 \mathrm{~m} / \mathrm{s}$, when the flow a

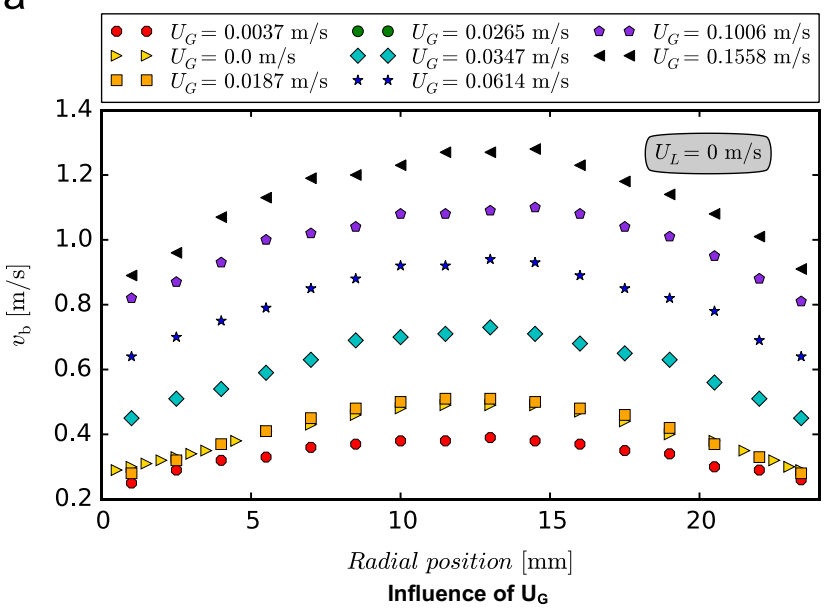

b

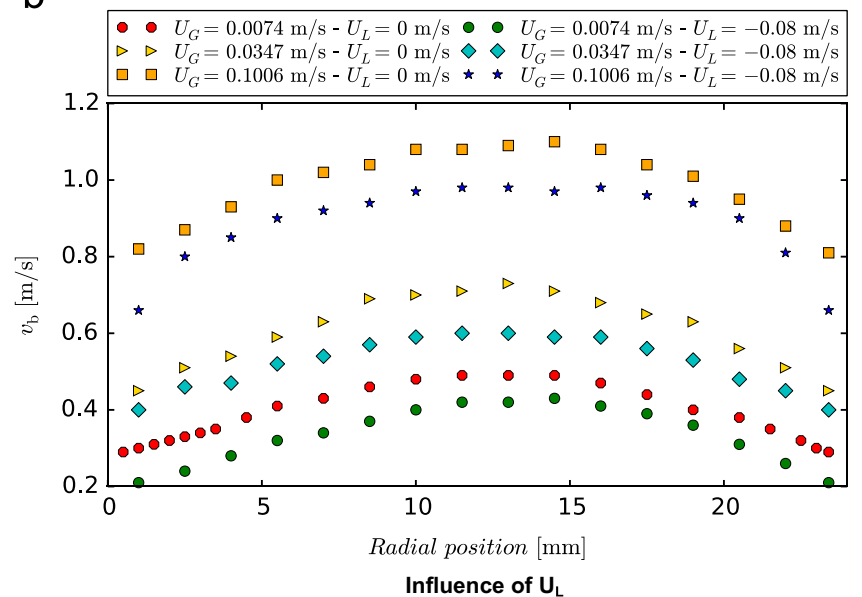

Fig. 17. Radial optical probe measurements: bubble rise velocity.

regime transition occurs, the bubble mean diameter increases as a consequence of the larger bubbles. Considering the counter-current operating condition (Fig. 18b), for the same gas velocity, the mean diameter decreases. This result is particularly interesting and may be related to the enhanced breakup due to the higher turbulence in the pipe. However, no quantitative data are available to support this hypothesis and will be a matter for future studies. 
a

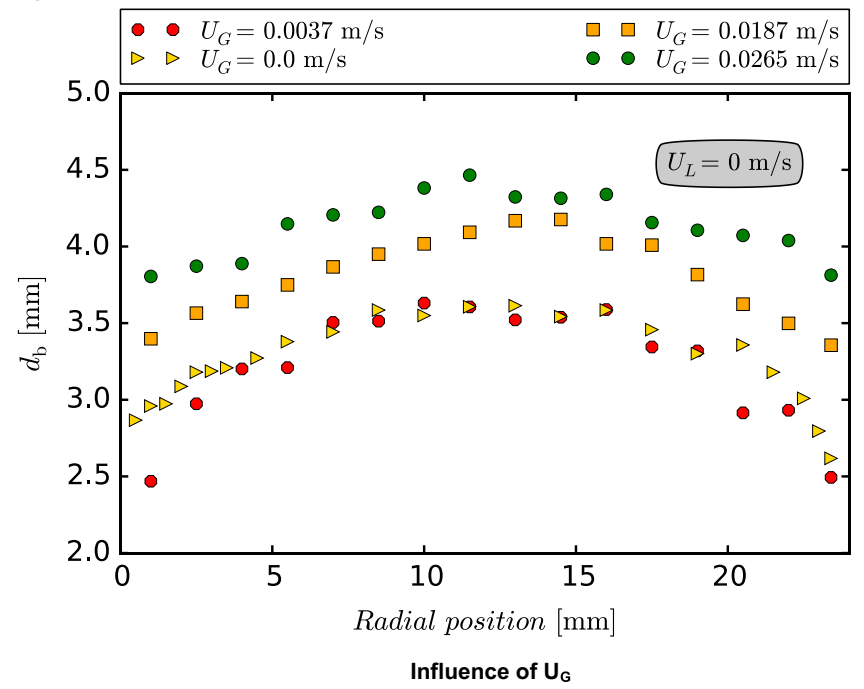

b

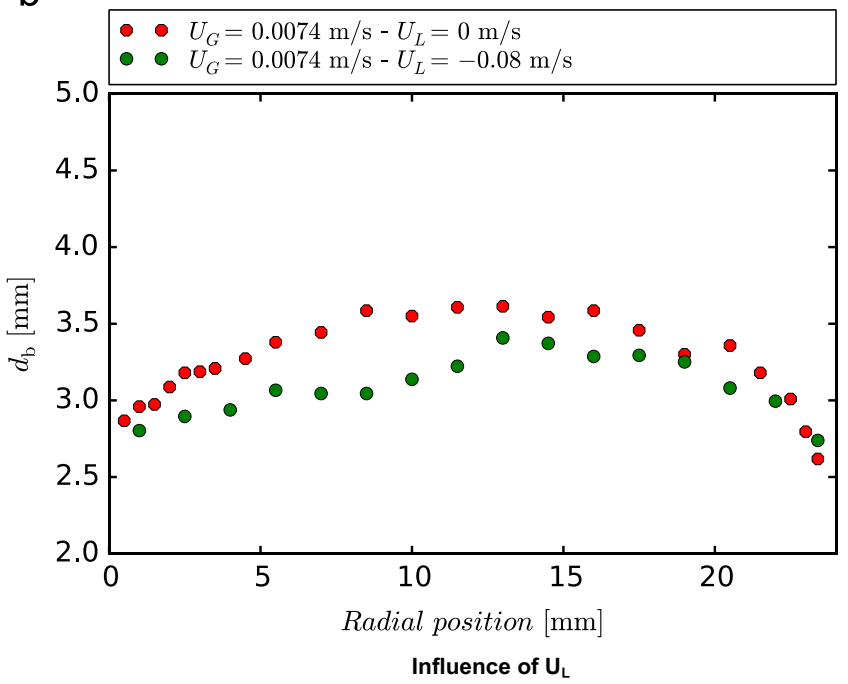

Fig. 18. Radial optical probe measurements: bubble mean diameter.

Table 5

Comparison between local and global holdup values.

\begin{tabular}{lllll}
\hline$U_{G}[\mathrm{~m} / \mathrm{s}]$ & $U_{L}[\mathrm{~m} / \mathrm{s}]$ & $\left\langle\varepsilon_{G}>[\%]\right.$ & $\varepsilon_{G}[\%]$ & Relative error $^{\mathrm{a}}[\%]$ \\
\hline 0.0037 & 0 & 0.0129 & 0.0140 & 7.77 \\
0.0074 & 0 & 0.0246 & 0.0284 & 13.29 \\
$0.0187^{\mathrm{b}}$ & 0 & 0.0584 & 0.0703 & 16.84 \\
0.0265 & 0 & 0.0742 & 0.0891 & 16.74 \\
0.0347 & 0 & 0.0922 & 0.1069 & 13.71 \\
0.0614 & 0 & 0.1295 & 0.1487 & 12.91 \\
0.1006 & 0 & 0.1718 & 0.1918 & 10.44 \\
0.1558 & 0 & 0.2368 & 0.2341 & -1.15 \\
0.0074 & -0.080 & 0.0341 & 0.0423 & 19.20 \\
0.0347 & -0.080 & 0.0628 & 0.1335 & 52.96 \\
0.1011 & -0.080 & 0.1211 & 0.1963 & 38.32 \\
\hline
\end{tabular}

a Computed using: $100 \cdot \frac{\varepsilon_{G}-<\varepsilon_{G}>}{\varepsilon_{G}}$.

b Flow regime transition.

\section{Conclusions}

In this paper, a counter-current gas-liquid large-diameter bubble column is experimentally studied in the annular gap (AG) and open tube (OT) configurations. The experimental facility is a column with an inner diameter of $0.24 \mathrm{~m}$, and the hydrodynamic properties are studied using gas holdup measurements and double-fiber optical probes.
The bed expansion technique was used to obtain gas holdup measurements. In both the AG and OT configurations, the gas holdup increases linearly as a function of the gas flow rate in the homogeneous regime, followed by a change in slope due to flow regime transition. Moreover, the holdup in the homogeneous regime increases with water flow rate in the counter-current operating condition. In the transition/heterogeneous regime, the water superficial velocity has no influence on the holdup in the AG configuration. The counter-current mode was found to destabilize the homogeneous regime: the transitional velocity decreases with increasing liquid velocity. In addition, the OT configuration is characterized by lower transitional velocities compared to the AG configuration. The holdup curves in the AG and OT configurations are similar in shape and values, suggesting that the presence of internals has a limited influence on the global column hydrodynamic. The presence of the internals stabilize the homogeneous flow regime in terms of transition gas velocity and transition holdup value. Finally, the holdup measurements were compared with existing data and correlations from the literatures, and a new correlation was developed using non-dimensional analysis.

A double-fiber optical probe was used to acquire midpoint data and radial profiles of the local flow characteristics to relate the global hydrodynamics of the system to the local flow properties. The local void fraction profiles are center peaked also in the homogeneous regime. Increased gas flow rates resulted in greater profile curvature from the column wall to the center, particularly after the flow regime transition. The counter-current operating condition is found to increase the holdup and to decrease the bubble velocity. The flow regime transition has also been observed in the local measurements comparing the holdup to the local void fraction, analyzing the local swarm velocity, the bubble rise velocity and the Sauter mean diameter.

In conclusion, this paper contributes to the existing discussion on the influence of the internals on bubble column hydrodynamics. The experimental results are of practical interest in the design of bubble columns and are particularly useful for models validation. For example, the dataset may be used for developing a drift-flux model of the bubble column or to validate Computational Fluid Dynamics models.

\section{Nomenclature}

\section{Acronyms}

AG Annular Gap bubble column

OT Open Tube bubble column

Symbols

$A^{*}, B^{*} \quad$ Parameters in the Reilly correlation [dimensionless]

$d_{\text {holes }} \quad$ Gas sparger holes diameter [mm]

$d_{c} \quad$ Diameter of the column [m]

$d_{b} \quad$ Sauter mean diameter from the optical probe [mm]

$d_{b \text {, Corrected }}$ Sauter mean diameter from the optical probe applying the aspect ratio correction [mm]

$D_{H}^{*} \quad$ Non-dimensional diameter [dimensionless]

$D_{\mathrm{H}, \mathrm{Cr}}^{*} \quad$ Critical non-dimensional diameter [dimensionless]

$f \quad$ Bubble frequency [dimensionless]

$n, k_{1}{ }^{*}, k_{1}, k_{2}, k_{3}$ Parameters in the holdup correlation [dimensionless]

$h_{\text {probe }} \quad$ Height of the probe from the bottom of the column [m]

$H_{c} \quad$ Height of the column [m]

$H_{D} \quad$ Heights of the free-surface after aeration [m]

$H_{0} \quad$ Heights of the free-surface before aeration [m] 
$J \quad$ Drift flux $[\mathrm{m} / \mathrm{s}]$

g Gravity acceleration $\left[\mathrm{m} / \mathrm{s}^{2}\right]$

Q Volumetric flow rate $\left[\mathrm{m}^{3} / \mathrm{s}\right]$

$R_{c} \quad$ Radius of the column [m]

$S \quad$ Parameter in the swarm velocity method [dimensionless]

$u_{b} \quad$ Bubble rise velocity $[\mathrm{m} / \mathrm{s}]$

$u_{\infty} \quad$ Terminal bubble velocity $[\mathrm{m} / \mathrm{s}]$

$U_{b} \quad$ Parameter in the drift flux methods $[\mathrm{m} / \mathrm{s}]$

$U \quad$ Superficial velocity $[\mathrm{m} / \mathrm{s}]$

$v \quad$ Local phase phase velocity

$\mu \quad$ Dynamic viscosity [Pa s]

$\sigma \quad$ Surface tension [N/m]

$\varphi \quad$ Aspect ratio [dimensionless]

$\varepsilon_{G} \quad$ Gas Holdup [dimensionless]

$\varepsilon_{G, \text { Local }}$ Local void fraction [dimensionless]

$\left.<\varepsilon_{G}\right\rangle$ Integrated gas holdup [dimensionless]

$\Delta t_{\text {sampling }}$ Optical probe sampling time [s]

\section{Subscripts}

$\begin{array}{ll}L & \text { Liquid phase } \\ G & \text { Gas phase } \\ T, E & \text { Subscripts in the drift flux formulation } \\ \text { trans } & \text { Transition point } \\ \text { swarm } & \text { Swarm velocity }\end{array}$

\section{Appendix A. Notes on the Wallis method}

Herein, the detailed derivation of the Wallis method for the identification of flow regime transition is proposed. This methods was firstly derived in by Wallis (1969) in the early 1955 and, despite it is widely used in the literature, often there is confusion in its definition. The goal of this section is to briefly show the derivation of the method, which may be helpful for other researchers.

At first, we start considering the two-phase from a local point of view. We define the volumetric flux. The flux is a vector quantity, but, in the following, it will be used to represent the scalar component in the direction of the motion along the pipe. The flux is related to the local holdup and to the local phase velocity as follows:

$J_{L}=\left.\left(1-\varepsilon_{G}\right) v_{L}\right|_{\text {Local }}$

$J_{G}=\left.\varepsilon_{G} v_{G}\right|_{\text {Local }}$

The total local flux is, then:

$J=J_{L}+J_{G}$

The local volumetric fluxes are related to the volumetric flow rates as:

$Q_{L}=\int J_{L} d A$

$Q_{G}=\int J_{G} d A$

Before processing, it is worth reminding the definition of the superficial velocities:

$U_{L}=\frac{Q_{L}}{A}$

$U_{G}=\frac{Q_{G}}{A}$
Considering a one-dimensional approach, the variables are cross sectional averaged. It follows:

$J_{L}=U_{L}=\frac{Q_{L}}{A}$

$J_{G}=U_{G}=\frac{Q_{G}}{A}$

Therefore, the phase velocities, in a one-dimensional approach, reads:

$v_{L}=\frac{U_{L}}{\left(1-\varepsilon_{G}\right)}$

$v_{G}=\frac{U_{G}}{\varepsilon_{G}}$

The relative velocity between the phases, $v_{G-L}$, is:

$v_{G-L}=\left(v_{G}-v_{L}\right)=-v_{L-G}$

Drift velocities are defined as the difference between the phases velocities and the average as follows:

$v_{G->J}=v_{G}-J$

$v_{L->J}=v_{L}-J$

The drift flux, represents the volumetric flux of one phase relative to a surface moving at the average velocity. For the gas and liquid phase it reads:

$J_{G->L}=\varepsilon_{G}\left(v_{G}-J\right)$

$J_{L->G}=\left(1-\varepsilon_{G}\right)\left(v_{L}-J\right)$

Substituting Eq. (A.3) into Eq. (A.15) and using Eq. (A.2) (considering Eq. (A.8) and Eq. (A.9)), it follows, for the gas phase:

$J_{G->L}=U_{G}-\varepsilon_{G}\left(U_{L}-U_{G}\right)=U_{G}\left(1-\varepsilon_{G}\right)-U_{L} \varepsilon_{G}$

Similarly, for the liquid phase:

$J_{G->L}=U_{L} \varepsilon_{G}-U_{G}\left(1-\varepsilon_{G}\right)$

Therefore:

$J_{G->L}=-J_{L->G}=J_{T}$

Substituting for $U_{G}$ and $U_{L}$ in Eq. (A.18) by using Eqs. (A.10) and (A.11), we obtain a relation between the drift flux and the relative phase velocity:

$J_{G->L}=J_{T}=\varepsilon_{G}\left(1-\varepsilon_{G}\right)\left(v_{L}-v_{G}\right)=\varepsilon_{G}\left(1-\varepsilon_{G}\right) v_{L-G}$

\section{Appendix B. Holdup correlations}

In this appendix we provide the details for the correlations presented in Section 3.1.2.

- Hughmark (1967):

$$
\varepsilon_{G}=\frac{1}{2+\left(\frac{0.35}{U_{G}}\right)\left[\frac{\rho_{L} \sigma}{72}\right]^{1 / 3}}
$$

○ Column design. $d_{c}=0.025-1.067-\mathrm{m}, U_{G}=0.004-0.45 \mathrm{~m} / \mathrm{s}$;

- Phases. Air-Water, Air- $\mathrm{Na}_{2} \mathrm{CO}_{3}$ aq. soln, Air-Kerosene, AirLight oil, Air-Glycerol, Air- $\mathrm{ZnCl}_{2}$ aq. Soln.;

○ Properties. $\rho_{L}=780-1700 \mathrm{~kg} / \mathrm{m}^{3}, \quad \mu_{L}=0.0009-0.152$ Pa s, $\sigma=0.025-0.076 \mathrm{~N} / \mathrm{m}$.

- Mashelkar (1970) as reported by Gopal and Sharma (1983):

$\varepsilon_{G}=\frac{U_{G}}{0.3+2 U_{G}}$

$\circ$ Column design. $U_{G}=0.1-0.3 \mathrm{~m} / \mathrm{s}, H_{c} / d_{c}=3-12$; 
- Phases. Air-Water.

- Akita and Yoshida (1973):

$\frac{\varepsilon_{G}}{\left(1-\varepsilon_{G}\right)^{4}}=c_{1}\left(\frac{g d_{c}^{2} \rho_{L}}{\sigma}\right)^{1 / 8}\left(\frac{g d_{c}^{3}}{\nu_{L}^{2}}\right)^{1 / 12}\left(\frac{U_{G}}{\sqrt{g d_{c}}}\right)$

where $c_{1}=0.20$ for non-electrolyte systems and $c_{1}=0.25$ for electrolyte solution, which causes a slightly larger gas holdup due to the influence of electrolyte concentration on bubble column. The reader may refer, for example, to the discussion of Besagni and Inzoli (2015)

○ Column design. $d_{c}=0.152-0.60 \mathrm{~m}, U_{G}=0.003-0.40 \mathrm{~m} / \mathrm{s}$, $H_{c}=1.26-3.5 \mathrm{~m}$;

- Phases. Air-Water, Air-Glycol aq. soln., Air-Methanol, Air$\mathrm{CCl}_{4}$,Air- $\mathrm{Na}_{2} \mathrm{SO}_{3}$ aq. soln., Air-NaCl aq. soln., $\mathrm{O}_{2}$-Water, HeWater, $\mathrm{CO}_{2}$-Water;

○ Properties. $\rho_{L}=800-1600 \mathrm{~kg} / \mathrm{m}^{3}, \mu_{L}=0.00058-0.0211$ Pa s, $\sigma=0.022-0.0742 \mathrm{~N} / \mathrm{m}$,

- Hikita and Kikukawa (1974):

$$
\varepsilon_{G}=0.505 \cdot U_{G}^{0.47}\left(\frac{72}{\sigma}\right)^{2 / 3}\left(\frac{1}{\mu_{L}}\right)^{0.05}
$$

○ Column design. $d_{c}=0.10-0.19 \mathrm{~m}, U_{G}=0.0043-0.338 \mathrm{~m} / \mathrm{s}$, $H_{c}=1.5-2.4 \mathrm{~m}$;

- Phases. Air-Water, Air-Methanol aq. soln., Air-Cane Sugar;

○ Properties. $\rho_{L}=911-1233 \mathrm{~kg} / \mathrm{m}^{3}, \quad \mu_{L}=0.001-0.0192$ Pa s, $\sigma=0.0382-0.0755 \mathrm{~N} / \mathrm{m}$.

- Sada et al. (1984):

$$
\frac{\varepsilon_{G}}{\left(1-\varepsilon_{G}\right)^{4}}=0.32 \cdot\left(\frac{g d_{c}^{2} \rho_{L}}{\sigma}\right)^{0.121}\left(\frac{g d_{c}^{3}}{\nu_{L}^{2}}\right)^{0.086}\left(\frac{U_{G}}{\sqrt{g d_{c}}}\right)\left(\frac{\rho_{G}}{\rho_{L}}\right)^{0.068}
$$

○ Column design. $d_{c}=0.073 \mathrm{~m}, U_{G}=0.00546-0.074 \mathrm{~m} / \mathrm{s}$, $H_{c}=0.95 \mathrm{~m}$;

- Phases. Air-Water, Water- $\mathrm{N}_{2}$, Water-He, Water- $\mathrm{CO}_{2}$, Methanol- $\mathrm{N}_{2}, \mathrm{NaNO}_{3}-\mathrm{N}_{2}, \mathrm{NaNO}_{3}-\mathrm{He}, \mathrm{LiCl}-\mathrm{KCl}-\mathrm{N}_{2}, \mathrm{LiCl}-\mathrm{KCl}-$ He;

○ Properties. $\rho_{L}=788-1880 \mathrm{~kg} / \mathrm{m}^{3}, \mu_{L}=0.00045-0.00365$ Pa s, $\sigma=0.0215-0.130 \mathrm{~N} / \mathrm{m}$.

- Reilly et al. (1986):

$\varepsilon_{G}=296 \cdot U_{G}^{0.44} \rho_{L}^{-0.98} \sigma^{-0.16} \rho_{G}^{0.19}+0.009$

○ Column design. $d_{c}=0.30 \mathrm{~m}, U_{G}=0.00673-0.097 \mathrm{~m} / \mathrm{s}$ (airwater), $H_{c}=0.50 \mathrm{~m}$;

- Phases. Air-water, Air-Varsol, Air-trichloroethylene;

○ Properties. $\rho_{L}=788-1450 \mathrm{~kg} / \mathrm{m}^{3}, \quad \mu_{L}=0.000552-0.0014$ 52 Pa s, $\sigma=0.0283-0.0720 \mathrm{~N} / \mathrm{m}$.

- Kawase and Moo-Young (1987):

$$
\varepsilon_{G}=1.07 \cdot n^{2 / 3}\left(\frac{U_{G}^{2}}{g d_{c}}\right)^{1 / 3}
$$

where $n$ depends on the liquid phase

○ Column design. $d_{c}=0.23 \mathrm{~m} U_{G}=0.00812-0.0565 \mathrm{~m} / \mathrm{s}$ (airwater), $H_{c}=1.22 \mathrm{~m}$;

- Phases. Air-water, Air-glycerine, Air-dextrose aq. soln, Airthree fermentation media (glucose + mineral salt, molasses + mineral salt, Alpha-floc + mineral salt);

○ Properties. $\rho_{L}=991-1009 \mathrm{~kg} / \mathrm{m}^{3}$.

\section{References}

Akita, K., Yoshida, F., 1973. Gas holdup and volumetric mass transfer coefficient in bubble columns. effects of liquid properties. Ind. Eng. Chem. Process. Des. Dev. $12,76-80$.

Al-Oufi, F.M., Cumming, I.W. Rielly, C.D., 2010. Destabilisation of homogeneous bubbly flow in an annular gap bubble column. Can. J. Chem. Eng. 88, 482-490.

Al-Oufi, F.M., Rielly, C.D., Cumming, I.W., 2011. An experimental study of gas void fraction in dilute alcohol solutions in annular gap bubble columns using a fourpoint conductivity probe. Chem. Eng. Sci. 66, 5739-5748.

Baawain, M.S., El-Din, M.G., Smith, D.W., 2007. Artificial neural networks modeling of ozone bubble columns: mass transfer coefficient, gas hold-up, and bubble size. Ozone: Sci. Eng. 29, 343-352.

Barrau, E., Rivière, N., Poupot, C., Cartellier, A., 1999. Single and double optical probes in air-water two-phase flows: real time signal processing and sensor performance. Int. J. Multiph. Flow 25, 229-256.

Besagni, G., Guédon, G., Inzoli, F., 2014. Experimental investigation of counter current air-water flow in a large diameter vertical pipe with inners. J. Phys.: Conf. Ser. 547, 012024.

Besagni, G., Guédon, G.R., Inzoli, F., 2015. Annular gap bubble column: experimental investigation and computational fluid dynamics modeling. J. Fluids Eng. 138, 011302.

Besagni, G., Inzoli, F., 2015. Influence of electrolyte concentration on holdup, flow regime transition and local flow properties in a large scale bubble column. J. Phys.: Conf. Ser. 655, 012039.

Besagni, G., Inzoli, F., 2016. Bubble size distributions and shapes in annular gap bubble column. Exp. Therm. Fluid Sci. 74, 27-48.

Biń, A.K., Duczmal, B., Machniewski, P., 2001. Hydrodynamics and ozone mass transfer in a tall bubble column. Chem. Eng. Sci. 56, 6233-6240.

Brooks, C.S., Paranjape, S.S., Ozar, B., Hibiki, T., Ishii, M., 2012. Two-group drift-flux model for closure of the modified two-fluid model. Int. J. Heat Fluid Flow 37, 196-208.

Carleton, A.J., Flain, R.J., Rennie, J., Valentin, F.H.H., 1967. Some properties of a packed bubble column. Chem. Eng. Sci. 22, 1839-1845.

Cartellier, A., Barrau, E., 1998. Monofiber optical probes for gas detection and gas velocity measurements: conical probes. Int. J. Multiph. Flow 24, 1265-1294.

Chang, K.-A., Lim, H.-J., Su, C.B., 2003. Fiber optic reflectometer for velocity and fraction ratio measurements in multiphase flows. Rev. Sci. Instrum. 74, 3559-3565.

Chaumat, H., Billet-Duquenne, A.M., Augier, F., Mathieu, C., Delmas, H., 2005. Application of the double optic probe technique to distorted tumbling bubbles in aqueous or organic liquid. Chem. Eng. Sci. 60, 6134-6145.

Chaumat, H., Billet-Duquenne, A.M., Augier, F., Mathieu, C., Delmas, H., 2007. On the reliability of an optical fibre probe in bubble column under industrial relevant operating conditions. Exp. Therm. Fluid Sci. 31, 495-504.

Dargar, P., Macchi, A., 2006. Effect of surface-active agents on the phase holdups of three-phase fluidized beds. Chem. Eng. Process.: Process. Intensif. 45, 764-772.

Das, G., Das, P.K., Purohit, N.K., Mitra, A.K., 1999a. Flow pattern transition during gas liquid upflow through vertical concentric annuli-Part I: experimental investigations. J. Fluids Eng. 121, 895-901.

Das, G., Das, P.K., Purohit, N.K., Mitra, A.K., 1999b. Flow pattern transition during gas liquid upflow through vertical concentric annuli-part II: mechanistic models. J. Fluids Eng. 121, 902-907.

Deckwer, W.-D., Louisi, Y.,Zaidi, A., Ralek, M.,1980. Hydrodynamic properties of the Fischer-Tropsch slurry process. Ind. Eng. Chem. Process. Des. Dev. 19, 699-708.

Fair, J.R., Lambright, A.J., Andersen, J.W., 1962. Heat transfer and gas holdup in a sparged contactor. Ind. Eng. Chem. Process. Des. Dev. 1, 33-36.

Gopal, J.S., Sharma, M.M., 1983. Mass transfer characteristics of low H/D bubble columns. Can. J. Chem. Eng. 61, 517-526.

Hasan, A.R., Kabir, C.S., 1992. Two-phase flow in vertical and inclined annuli. Int. J. Multiph. Flow 18, 279-293.

Hasan, A.R., Kabir, C.S., 2010. Modeling two-phase fluid and heat flows in geothermal wells. J. Pet. Sci. Eng. 71, 77-86.

Hikita, H., Asai, S., Tanigawa, K., Segawa, K., Kitao, M., 1980. Gas hold-up in bubble columns. Chem. Eng. J. 20, 59-67.

Hikita, H., Kikukawa, H., 1974. Liquid-phase mixing in bubble columns: effect of liquid properties. Chem. Eng. J. 8, 191-197.

Hills, J.H., 1976. The operation of a bubble column at high throughputs: I. Gas holdup measurements. Chem. Eng. J. 12, 89-99.

Hughmark, G.A., 1967. Holdup and mass transfer in bubble columns. Ind. Eng. Chem. Process. Des. Dev. 6, 218-220.

Hur, Y.G., Yang, J.H., Jung, H., Park, S.B., 2013. Origin of regime transition to turbulent flow in bubble column: orifice- and column-induced transitions. Int. J. Multiph. Flow 50, 89-97.

Jhawar, A.K., Prakash, A., 2014. Bubble column with internals: effects on hydrodynamics and local heat transfer. Chem. Eng. Res. Des. 92, 25-33.

Jin, H., Yang, S., He, G., Wang, M., Williams, R.A., 2010. The effect of gas-liquid counter-current operation on gas hold-up in bubble columns using electrical resistance tomography. J. Chem. Technol. Biotechnol. 85, 1278-1283.

Joshi, J.B., Veera, U.P., Parasad, C.V., Phanikkumar, D.V., Deshphande, N.S., Thakre, S.S., Thorat, B.N., 1998. Gas holdup structure in bubble column reactors. PINSA 64A, 441-567.

Kantarci, N., Borak, F., Ulgen, K.O., 2005. Bubble column reactors. Process. Biochem. 40, 2263-2283. 
Kataoka, I., Ishii, M., 1987. Drift flux model for large diameter pipe and new correlation for pool void fraction. Int. J. Heat Mass Transf. 30, 1927-1939.

Kataoka, I., Ishii, M., Serizawa, A., 1986. Local formulation and measurements of interfacial area concentration in two-phase flow. Int. J. Multiph. Flow 12, 505-529.

Kato, Y., Nishiwaki, A., Fukuda, T., Tanaka, S., 1972. The behavior of suspended solid particles and liquid in bubble columns. J. Chem. Eng. Jpn. 5, 112-118.

Kawase, Y., Moo-Young, M., 1987. Theoretical prediction of gas hold-up in bubble columns with Newtonian and non-Newtonian fluids. Ind. Eng. Chem. Res. 26, 933-937.

Kelessidis, V.C., Dukler, A.E., 1989. Modeling flow pattern transitions for upward gas-liquid flow in vertical concentric and eccentric annuli. Int. J. Multiph. Flow $15,173-191$.

Kiambi, S.L., Duquenne, A.-M., Dupont, J.B., Colin, C., Risso, F., Delmas, H., 2003. Measurements of bubble characteristics: comparison between double optical probe and imaging. Can. J. Chem. Eng. 81, 764-770.

Koide, K., Morooka, S., Ueyama, K., Matsuura, A., Yamashita, F., Iwamoto, S., Kato, Y., Inoue, H., Shigeta, M., Suzuki, S., Akehata, T., 1979. Behavior of bubbles in large scale bubble column. J. Chem. Eng. Jpn. 12, 98-104.

Koide, K., Takazawa, A., Komura, M., Matsunaga, H., 1984. Gas holdup and volumetric liquid-phase mass transfer coefficient in solid-suspended bubble columns. J. Chem. Eng. Jpn. 17, 459-466.

Krishna, R., Urseanu, M.I., Dreher, A.J., 2000. Gas hold-up in bubble columns: influence of alcohol addition versus operation at elevated pressures. Chem. Eng. Process.: Process. Intensif. 39, 371-378.

Krishna, R., Wilkinson, P.M., Van Dierendonck, L.L., 1991. A model for gas holdup in bubble columns incorporating the influence of gas density on flow regime transitions. Chem. Eng. Sci. 46, 2491-2496.

Lage, A.C.V.M., Time, R.W., 2002. An Experimental and Theoretical Investigation of Upward Two-Phase Flow in Annuli.

Leonard, C., Ferrasse, J.H., Boutin, O., Lefevre, S., Viand, A., 2015. Bubble column reactors for high pressures and high temperatures operation. Chem. Eng. Res. Des. 100, 391-421.

Letzel, H.M., Schouten, J.C., Krishna, R., van den Bleek, C.M., 1999. Gas holdup and mass transfer in bubble column reactors operated at elevated pressure. Chem. Eng. Sci. 54, 2237-2246.

Lima Neto, I., Zhu, D., Rajaratnam, N., 2008. Air injection in water with different nozzles. J. Environ. Eng. 134, 283-294.

Lucas, D., Krepper, E., Prasser, H.M., 2003. Evolution of flow patterns, gas fraction profiles and bubble size distributions in gas-liquid flows in vertical tubes. Trans. Inst. Fluid-Flow Mach. 112, 37-46.

Lucas, D., Krepper, E., Prasser, H.M., Manera, A., 2006. Investigations on the stability of the flow characteristics in a bubble column. Chem. Eng. Technol. 29, 1066-1072.

Mashelkar, R., 1970. Bubble columns. Br. Chem. Eng. 15, 12971297.

Maurer, S., Wagner, E.C., van Ommen, J.R., Schildhauer, T.J., Teske, S.L., Biollaz, S.M. A., Wokaun, A., Mudde, R.F., 2015. Influence of vertical internals on a bubbling fluidized bed characterized by X-ray tomography. Int. J. Multiph. Flow. 75, 237-249.

Mudde, R.F., Harteveld, W.K., van den Akker, H.E.A., 2009. Uniform flow in bubble columns. Ind. Eng. Chem. Res. 48, 148-158.

Nedeltchev, S., 2015. New methods for flow regime identification in bubble columns and fluidized beds. Chem. Eng. Sci. 137, 436-446.

Nedeltchev, S., Shaikh, A., 2013. A new method for identification of the main transition velocities in multiphase reactors based on information entropy theory. Chem. Eng. Sci. 100, 2-14.

Nottenkamper, R., Steiff, A., Weinspach, P., 1983. Experimental investigation of hydrodynamics of bubble columns. Ger. Chem. Eng. 6, 147-155.

O'Dowd, W., Smith, D.N., Ruether, J.A., Saxena, S.C., 1987. Gas and solids behavior in a baffled and unbaffled slurry bubble column. AIChE J. 33, 1959-1970.

Ohki, Y., Inoue, H., 1970. Longitudinal mixing of the liquid phase in bubble columns. Chem. Eng. Sci. 25, 1-16.

Otake, T., Tone, S., Shinohara, K., 1981. Gas holdup in the bubble column with cocurrent and countercurrent gas-liquid flow. J. Chem. Eng. Jpn., 338-340.

Pjontek, D., Parisien, V., Macchi, A., 2014. Bubble characteristics measured using a monofibre optical probe in a bubble column and freeboard region under high gas holdup conditions. Chem. Eng. Sci. 111, 153-169.
Reilly, I., Scott, D., Debruijn, T., MacIntyre, D., 1994. The role of gas phase momentum in determining gas holdup and hydrodynamic flow regimes in bubble column operations. Can. J. Chem. Eng. 72, 3-12.

Reilly, I.G., Scott, D.S., De Bruijn, T., Jain, A., Piskorz, J., 1986. A correlation for gas holdup in turbulent coalescing bubble columns. Can. J. Chem. Eng. 64, 705-717.

Reith, T., Renken, S., Israel, B.A., 1968. Gas hold-up and axial mixing in the fluid phase of bubble columns. Chem. Eng. Sci. 23 (6), 619-629.

Ribeiro Jr, C.P., Mewes, D., 2007. The influence of electrolytes on gas hold-up and regime transition in bubble columns. Chem. Eng. Sci. 62, 4501-4509.

Richardson, J.F., Zaki, W.N., 1997. Sedimentation and fluidisation: part I. Chem. Eng. Res. Des. 75 (Supplement), S82-S100.

Rollbusch, P., Becker, M., Ludwig, M., Bieberle, A., Grünewald, M., Hampel, U., Franke, R., 2015. Experimental investigation of the influence of column scale, gas density and liquid properties on gas holdup in bubble columns. Int. J. Multiph. Flow. 75, 88-106.

Ruzicka, M.C., Draho/vs, J., Fialov/'a, M., Thomas, N.H., 2001. Effect of bubble column dimensions on flow regime transition. Chem. Eng. Sci. 56, 6117-6124.

Ruzicka, M.C., Drahoš, J., Mena, P.C., Teixeira, J.A., 2003. Effect of viscosity on homogeneous-heterogeneous flow regime transition in bubble columns. Chem. Eng. J. 96, 15-22.

Sada, E., Katoh, S., Yoshii, H., Yamanishi, T., Nakanishi, A., 1984. Performance of the gas bubble column in molten salt systems. Ind. Eng. Chem. Process. Des. Dev. 23, 151-154.

Sarrafi, A., Müller-Steinhagen, H., Smith, J.M., Jamialahmadi, M., 1999. Gas holdup in homogeneous and heterogeneous gas-liquid bubble column reactors. Can. J Chem. Eng. 77, 11-21.

Schumpe, A., Grund, G., 1986. The gas disengagement technique for studying gas holdup structure in bubble columns. Can. J. Chem. Eng. 64, 891-896.

Shah, Y.T., Kelkar, B.G., Godbole, S.P., Deckwer, W.D., 1982. Design parameters estimations for bubble column reactors. AIChE J. 28, 353-379.

Shaikh, A., Al-Dahhan, M., 2013. Scale-up of bubble column reactors: a review of current state-of-the-art. Ind. Eng. Chem. Res. 52, 8091-8108.

Sharaf, S., Zednikova, M., Ruzicka, M.C., Azzopardi, B.J., 2016. Global and local hydrodynamics of bubble columns - effect of gas distributor. Chem. Eng. J. 288, 489-504.

Shawkat, M.E., Ching, C.Y., 2011. Liquid turbulence kinetic energy budget of cocurrent bubbly flow in a large diameter vertical pipe. J. Fluids Eng. 133, 091303.

Shiea, M., Mostoufi, N., Sotudeh-Gharebagh, R., 2013. Comprehensive study of regime transitions throughout a bubble column using resistivity probe. Chem. Eng. Sci. 100, 15-22.

Simonnet, M., Gentric, C., Olmos, E., Midoux, N., 2007. Experimental determination of the drag coefficient in a swarm of bubbles. Chem. Eng. Sci. 62, 858-866.

Thorat, B.N., Shevade, A.V., Bhilegaonkar, K.N., Aglawe, R.H., Parasu Veera, U. Thakre, S.S., Pandit, A.B., Sawant, S.B., Joshi, J.B., 1998. Effect of sparger design and height to diameter ratio on fractional gas hold-up in bubble columns. Chem. Eng. Res. Des. 76 (7), 823-834.

Urseanu, M.I., 2000. Scaling up bubble column reactors.

Vejražka, J., Večeř, M., Orvalho, S., Sechet, P., Ruzicka, M.C Cartellier, A., 2010. Measurement accuracy of a mono-fiber optical probe in a bubbly flow. Int J. Multiph. Flow. 36, 533-548.

Wallis, G.B., 1969. One-dimensional two-phase flow, New York.

Wilkinson, P.M., Spek, A.P., van Dierendonck, L.L., 1992. Design parameters estimation for scale-up of high-pressure bubble columns. AIChE J. 38, 544-554.

Yamaguchi, K., Yamazaki, Y., 1982. Characteristics of counter current gas-liquid two-phase flow in vertical tubes. J. Nucl. Sci. Technol. 19, 985-996.

Yamashita, F., 1987. Effects of vertical pipe and rod internals on gas holdup in bubble columns. J. Chem. Eng. Jpn. 20, 204-206.

Yoshida, F., Akita, K., 1965. Performance of gas bubble columns: volumetric liquidphase mass transfer coefficient and gas holdup. AIChE J. 11, 9-13.

Youssef Ahmed, A., Al-Dahhan Muthanna, H., Dudukovic Milorad, P., 2013. Bubble columns with internals: a review. Int. J. Chem. React. Eng., 169.

Zahradnik, J., Fialova, M., Rruvzivc, k, M., Drahovs, J., Kavstanek, F., Thomas, N.H. 1997. Chem. Eng. Sci. 52, 3811-3826.

Zhang, W., Zhu, D.Z., 2013. Bubble characteristics of air-water bubbly jets in crossflow. Int. J. Multiph. Flow 55, 156-171.

Zuber, N., Findlay, J.A., 1965. Average volumetric concentration in two-phase flow systems. J. Heat Transf. 87, 453-468. 